ARTICLE

https://doi.org/10.1038/s41467-019-14186-y

\title{
Kindlin-2 modulates MafA and $\beta$-catenin expression to regulate $\beta$-cell function and mass in mice
}

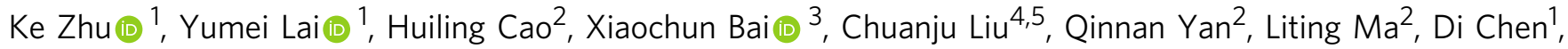
Giedrius Kanaporis (10 ${ }^{6}$, Junqi Wang (10) ${ }^{2}$, Luyuan $\mathrm{Li}^{7}$, Tao Cheng $\mathbb{1}^{8}{ }^{8}$, Yong Wang ${ }^{9}$, Chuanyue Wu (i) ${ }^{10 \star} \&$ Guozhi Xiao (10) 2,11*

$\beta$-Cell dysfunction and reduction in $\beta$-cell mass are hallmark events of diabetes mellitus. Here we show that $\beta$-cells express abundant Kindlin-2 and deleting its expression causes severe diabetes-like phenotypes without markedly causing peripheral insulin resistance. Kindlin-2, through its $\mathrm{C}$-terminal region, binds to and stabilizes MafA, which activates insulin expression. Kindlin-2 loss impairs insulin secretion in primary human and mouse islets in vitro and in mice by reducing, at least in part, $\mathrm{Ca}^{2+}$ release in $\beta$-cells. Kindlin- 2 loss activates GSK-3 $\beta$ and downregulates $\beta$-catenin, leading to reduced $\beta$-cell proliferation and mass. Kindlin-2 loss reduces the percentage of $\beta$-cells and concomitantly increases that of $\alpha$-cells during early pancreatic development. Genetic activation of $\beta$-catenin in $\beta$-cells restores the diabetes-like phenotypes induced by Kindlin-2 loss. Finally, the inducible deletion of $\beta$-cell Kindlin-2 causes diabetic phenotypes in adult mice. Collectively, our results establish an important function of Kindlin-2 and provide a potential therapeutic target for diabetes.

\footnotetext{
${ }^{1}$ Department of Orthopedic Surgery, Rush University Medical Center, Chicago, IL 60612, USA. ${ }^{2}$ Guangdong Provincial Key Laboratory of Cell Microenvironment and Disease Research, Shenzhen Key Laboratory of Cell Microenvironment, and Department of Biology, Southern University of Science and Technology, 518055 Shenzhen, China. ${ }^{3}$ Department of Cell Biology, School of Basic Medical Sciences, Southern Medical University, 510515 Guangzhou, China. ${ }^{4}$ Department of Orthopedic Surgery, New York University School of Medicine, New York, NY 10003, USA. ${ }^{5}$ Department of Cell Biology, New York University School of Medicine, New York, NY 10016, USA. ${ }^{6}$ Department of Molecular Biophysics and Physiology, Rush University Medical Center, Chicago, IL 60612, USA. ${ }^{7}$ State Key Laboratory of Medicinal Chemical Biology and Nankai University College of Pharmacy, 300071 Tianjin, China. ${ }^{8}$ State Key Laboratory of Experimental Hematology, Institute of Hematology and Blood Disease Hospital, Center for Stem Cell Medicine, Chinese Academy of Medical Sciences \& Peking Union Medical College, 300020 Tianjin, China. ${ }^{9}$ UVA Islet Microfluidic Laboratory, Department of Surgery, the University of Virginia, Charlottesville, VA 22908, USA. ${ }^{10}$ Department of Pathology, University of Pittsburgh, Pittsburgh, PA 15261, USA. ${ }^{11}$ Department of Orthopedic Surgery, Rush University Medical Center, Chicago, IL 60612, USA. *email: carywu@pitt.edu; xiaogz@sustech.edu.cn
} 
D iabetes mellitus (DM) is a group of metabolic diseases characterized by prolonged hyperglycemia with complications involving multiple critical organs. Both the incidence and prevalence of DM are high and steadily increasing worldwide. DM results from dysfunction and death of the insulinproducing pancreatic $\beta$-cells. Understanding the mechanisms that regulate processes, such as insulin expression and secretion as well as maintenance of $\beta$-cell mass, are of paramount biological and clinical importance, as they explain how these processes regulate metabolic homeostasis under physiological conditions and how their activities malfunction under diseased states, such as DM.

The transcription of the insulin gene is regulated by a number of factors, including MafA, Pax6, Pdx1, and Beta2 ${ }^{1-4}$. Among those, MafA, a member of the Maf family of basic-leucine zipper transcription factors that is exclusively expressed in the pancreatic $\beta$-cells and $l^{5-7}$, is a key regulator in coordinating and controlling insulin gene expression ${ }^{8}$. Interestingly, MafA is also required for the expression of $\operatorname{Pdx} 1$ and Beta2 ${ }^{9}$. Furthermore, MafA interacts with Pdx1 and Beta2 and synergistically activates insulin gene transcription ${ }^{8}$. In mice, loss of MafA causes glucose intolerance, leading to development of $\mathrm{DM}^{9}$. While the role of MafA in regulation of insulin expression is well documented in the literature, how its expression and activity are modulated is incompletely understood.

The secretion of insulin from $\beta$-cells is exquisitely regulated to meet metabolic demand through complex mechanisms that involve the integration and interaction of multiple external and internal stimuli. Blood glucose is the primary stimulus of insulin secretion from $\beta$-cells. After being taken up by $\beta$-cells through glucose transporter 2 , it stimulates insulin release through exocytosis by a process involving the influx of calcium ${ }^{10}$. While insulin resistance, a condition in which peripheral muscle and adipose tissues fail to respond to insulin properly, is necessary to cause type 2 diabetes (T2D), a decline in $\beta$-cell function, as demonstrated by inadequate insulin secretion in response to elevated blood glucose levels, becomes a hallmark of disease progression ${ }^{11,12}$. Furthermore, inadequate $\beta$-cell mass leads to insulin insufficiency, a contributor to the onset of hyperglycemia in both type 1 diabetes and T2D. Rulifson et al. reported that $\beta$ catenin expression is critical for $\beta$-cell proliferation and expansion and the maintenance of $\beta$-cell mass ${ }^{13}$. Key signals that control insulin secretion are poorly understood.

During pancreatic development and homeostasis, $\beta$-cell precursors must migrate to proper locations to form the islets of Langerhans and establish a suitable $\beta$-cell mass. Furthermore, $\beta$ cells must communicate with their extracellular matrix (ECM) to express and secret insulin in order to maintain glucose homeostasis. Kindlins are evolutionarily conserved cytoplasmic proteins that are key regulators of integrin-mediated cell-ECM adhesion, migration, and signaling ${ }^{14-19}$. In mammals, the Kindlin family consists of Kindlin-1, -2 , and -3 . They are encoded by three different genes, Kindlin-1 by Fermt1, Kindlin-2 by Fermt2, and Kindlin-3 by Fermt $3^{14,15,20,21}$. Each Kindlin protein contains a FERM ( $\mathrm{F}$ for 4.1 protein, $\mathrm{E}$ for ezrin, $\mathrm{R}$ for radixin, and $\mathrm{M}$ for moesin) domain that is responsible for interacting with $\beta$ integrin cytoplasmic tails $14,16,22-27$. Bledzka et al. reported that Kindlin-2 binds actin and regulates integrin outside-in signaling ${ }^{28}$. Genetic studies in humans reveal that mutations in the FERMT1 gene lead to Kindler syndrome, which is characterized by skin blistering ${ }^{21,29}$. Mutations in the FERMT3 gene impair integrin activation in humans, resulting in leukocyte adhesion deficiency-III, severe bleeding, frequent infections, and osteopetrosis $^{30-33}$. Global inactivation of Fermt2 in mice results in early embryonic lethality at E7.5 ${ }^{22}$. Conditional deletion of Fermt2 selectively in head and limb mesenchymal progenitors in mice causes severe chondrodysplasia and complete loss of the skull vault by impairing TGF- $\beta$ signaling and Sox 9 expression ${ }^{34}$. Zhang et al. showed that postnatal loss of Kindlin-2 causes progressive heart failure ${ }^{35}$. Our recent study demonstrated that Kindlin-2 associates with Rho GDP-dissociation Inhibitor a to suppress Racl activation and regulate podocyte structure and function in mice $^{18}$.

In this study, we use a conditional knockout strategy to delete Kindlin-2 expression in $\beta$-cells during pancreatic development in mice. Results from comprehensive analyses of control and mutant mice demonstrate a critical role for Kindlin- 2 in regulation of $\beta$ cell function and mass. In vitro and in vivo studies reveal that Kindlin-2 loss dramatically reduces insulin expression and secretion and impairs $\beta$-cell proliferation and mass, resulting in severe diabetes-like phenotypes. Kindlin-2 ablation markedly alters the islet composition by decreasing the percentage of $\beta$-cells and concomitantly increasing that of $\alpha$-cells during embryonic development. Mechanistically, Kindlin-2 activates insulin gene expression by interacting with and stabilizing MafA protein. Furthermore, Kindlin-2 loss activates GSK-3 $\beta$ and downregulates $\beta$-catenin. Inducible deletion of Kindlin- 2 in $\beta$-cells in adult mice causes similar diabetic phenotypes with impaired glucose tolerance and glucose-stimulated insulin secretion (GSIS), which are largely reversed by genetic upregulation of $\beta$-catenin in $\beta$-cells. Thus, we demonstrate that Kindlin-2, through its expression in $\beta$ cells, regulates glucose homeostasis by modulating insulin expression and secretion and $\beta$-cell mass through distinct molecular mechanisms.

\section{Results}

Kindlin-2 is highly expressed in pancreatic $\boldsymbol{\beta}$-cells. To investigate the potential role of Kindlin-2 in the pancreas, we performed immunofluorescent (IF) staining of mouse pancreatic sections using specific antibodies against Kindlin-2, glucagon, and insulin and observed that Kindlin-2 protein was highly expressed in the insulin-expressing $\beta$-cells, but not in the glucagon-expressing $\alpha$ cells located in the outer rim of the pancreatic islets (Fig. 1a). Furthermore, Kindlin-2 was weakly expressed in cells outside the islets (Fig. 1a). Kindlin-2 expression was markedly reduced in islets from aging (20-month-old) or high-fat diet-treated mice (Fig. 1b, c).

Kindlin-2 loss causes severe diabetes-like phenotypes. The $\beta$ cell-specific expression of Kindlin-2 observed above prompted us to investigate whether Kindlin-2 plays a role in $\beta$-cells. To do this, we deleted Kindlin-2 expression in $\beta$-cells by breeding the floxed Kindlin-2 (Kindlin- ${ }^{f l / f l}$ ) mice, in which exons 5 and 6 of the Kindlin-2 gene are flanked by two loxP sites ${ }^{34}$, with the RIP-Cre transgenic mice, in which the 668-bp rat insulin II gene promoter $(R I P)$ drives Cre expression in $\beta$-cells ${ }^{36}$, resulting in the $\beta$-cell conditional knockout mice, i.e., the Kindlin-2flfl; RIP-Cre mice (hereafter referred to as Kindlin-2RIP or K2-RIP). We performed the quantitative real-time reverse transcriptase-polymerase chain reaction (qPCR) analysis using RNAs isolated from islets of the two genotypes and observed that the level of Kindlin-2 mRNA was dramatically reduced in islets of K2-RIP mice relative to control littermates (Fig. 1d). Results from Western blotting (Fig. 1e, f) and IF staining of pancreatic sections (Fig. 1g) revealed that the level of Kindlin-2 protein was drastically decreased in K2RIP relative to control littermate islets. This reduction is specific because the Kindlin-2 expression in nonpancreatic tissues, such as kidney, muscle, liver, heart, and lung, was not significantly different in K2-RIP mice relative to control littermates (Fig. 1d-f). K2-RIP mice were born at the expected Mendelian frequency, and, starting at 2 weeks of age, displayed growth retardation (Fig. 1h, i). 

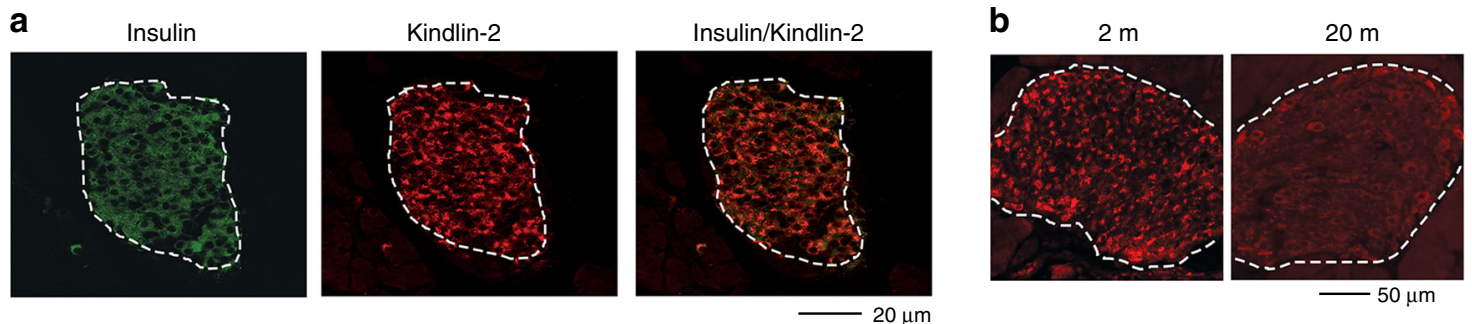

Glucagon
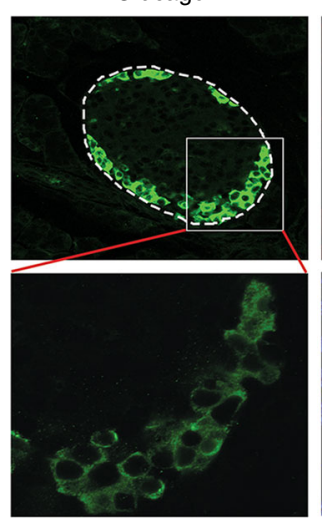

$-20 \mu \mathrm{m}$

d

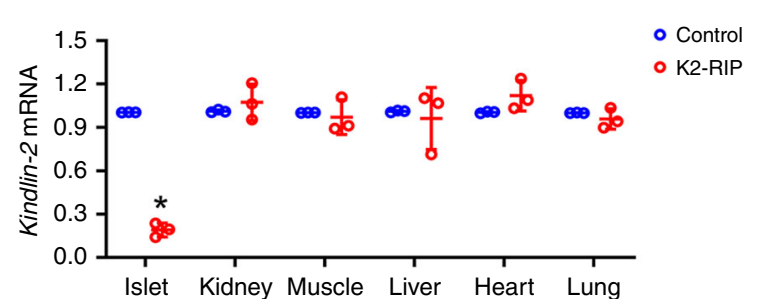

$\mathbf{f}$

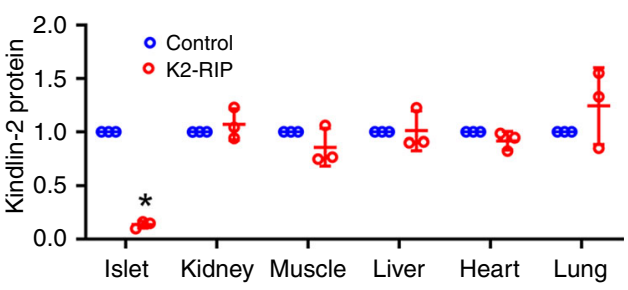

h Control K2-RIP

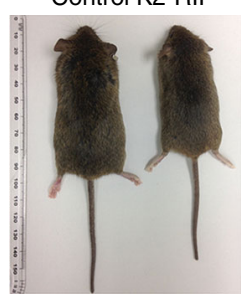

Kindlin-2
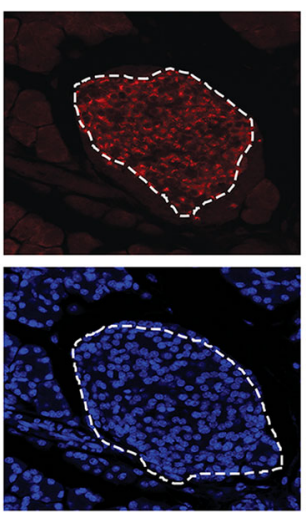

DAPI $50 \mu \mathrm{m}$
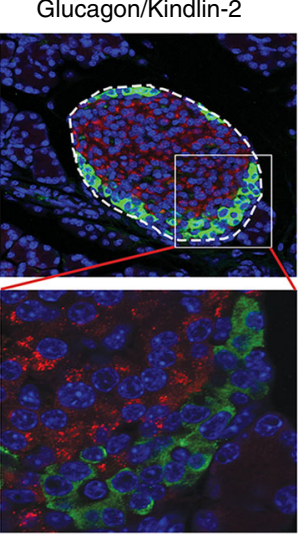

$20 \mu \mathrm{m}$ c

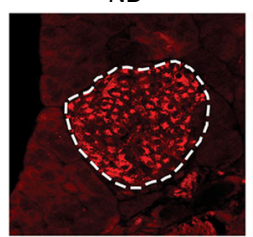

HFD

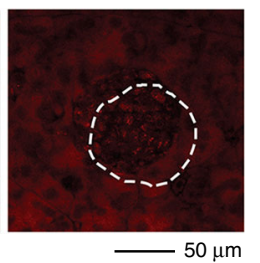

e

Islet Kidney Muscle Liver Heart Lung

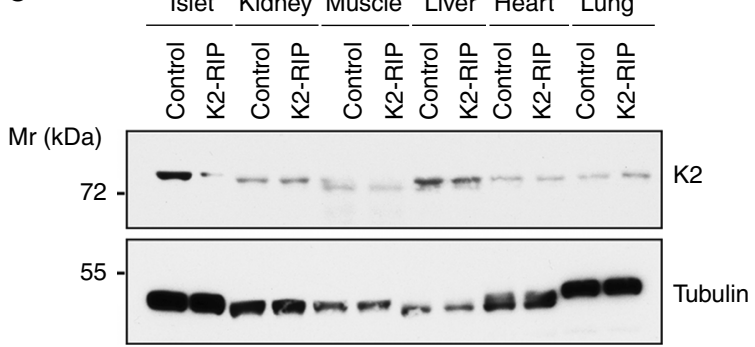

g

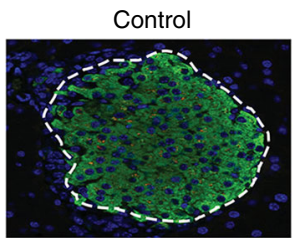

K2-RIP

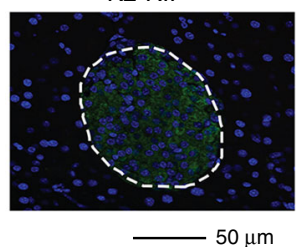

We next measured the level of fasting blood glucose and observed a significant elevation in 2- and 4-month-old male K2RIP mice compared with age- and sex-matched control littermates $(P<0.05$, Student's $t$ test) (Fig. 2a and Supplementary Fig. 1a). We further performed the glucose tolerance test (GTT). Mice were given a single intraperitoneal (i.p.) injection of glucose ( $2 \mathrm{~g} / \mathrm{kg}$ body weight) and blood samples were then taken to determine how quickly glucose was cleared from the blood.
Results revealed that the blood glucose levels were significantly increased in 2- and 4-month-old male K2-RIP mice compared with sex- and age-matched control groups at all time points (Fig. 2b and Supplementary Fig. 1b). The littermates generated from breeding, including the wild-type (WT) mice that contain no Cre or floxed Kindlin-2 genes, Kindlin-2 flox heterozygotes that harbor RIP-Cre (i.e., RIP-Cre; Kindlin- $2^{f l /+}$ ), Cre-negative floxed Kindlin-2 mice (i.e., Kindlin-2flfl) or Cre transgenic mice 
Fig. 1 Kindlin-2 is highly expressed in $\boldsymbol{\beta}$-cells and Kindlin-2 loss results in a growth retardation in mice. a Immunofluorescent (IF) staining. Sections of 2-month-old mouse pancreas were stained with anti-Kindlin-2 antibody, anti-insulin antibody, or anti-glucagon antibody (Sigma, G2654). Scale bar, 20 or $50 \mu \mathrm{m}$ as indicated. b IF staining of 2- (left) and 20-month-old (right) mouse pancreatic sections with Kindlin-2 antibody. Scale bar, $50 \mu \mathrm{m}$. c IF of pancreatic sections from mice treated with normal diet (ND) or high-fat diet (HFD) with Kindlin-2 antibody. Scale bar, $50 \mu \mathrm{m}$. d Quantitative real-time reverse transcriptase-polymerase chain reaction ( control littermates (RIP-Cre) were subjected to qPCR analyses for Kindlin-2 expression. Kindlin-2 mRNA was normalized to Gapdh mRNA. Statistical analyses (Student's $t$ test) were performed using the average values of triplicates from three independent experiments. ${ }^{\star} P<0.05$, versus control.

e, $\mathbf{f}$ Western blot analyses. Protein extracts isolated from the indicated tissues of 2-month-old male K2-RIP mice or control littermates (RIP-Cre) were subjected to Western blot analyses for Kindlin-2 expression. $\alpha$-Tubulin was used as a loading control. Quantitative data (f). Statistical analyses (Student's $t$ test) were performed using the average values of triplicates from three independent experiments. ${ }^{\star} P<0.05$, versus control. $\mathbf{g} \mathrm{IF}$ staining of pancreatic sections of 2-month-old male K2-RIP mice or control littermates (RIP-Cre) with Kindlin-2 antibody. Scale bar, $50 \mu \mathrm{m}$. $\mathbf{h}$ Gross appearance of 2-month-old male K2-RIP mice and control littermates (RIP-Cre). i Animal growth curve. $N=12$ for control, $N=11$ mice $K 2-R I P$, ${ }^{\star} P<0.05$, versus control, Student's $t$ test. Results are expressed as mean \pm standard deviation. Source data for $\mathbf{d}-\mathbf{f}$ are provided as a Source Data file.
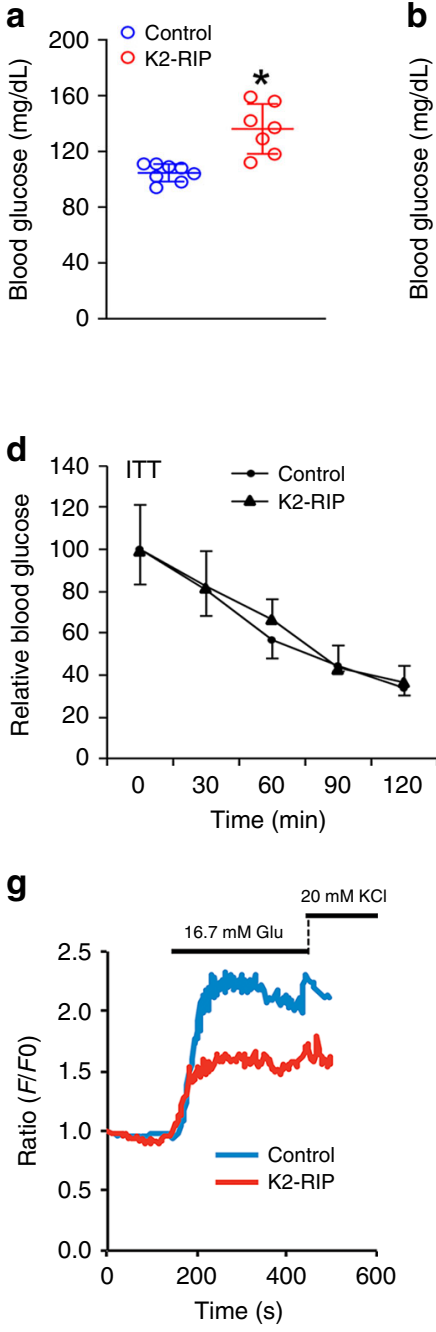
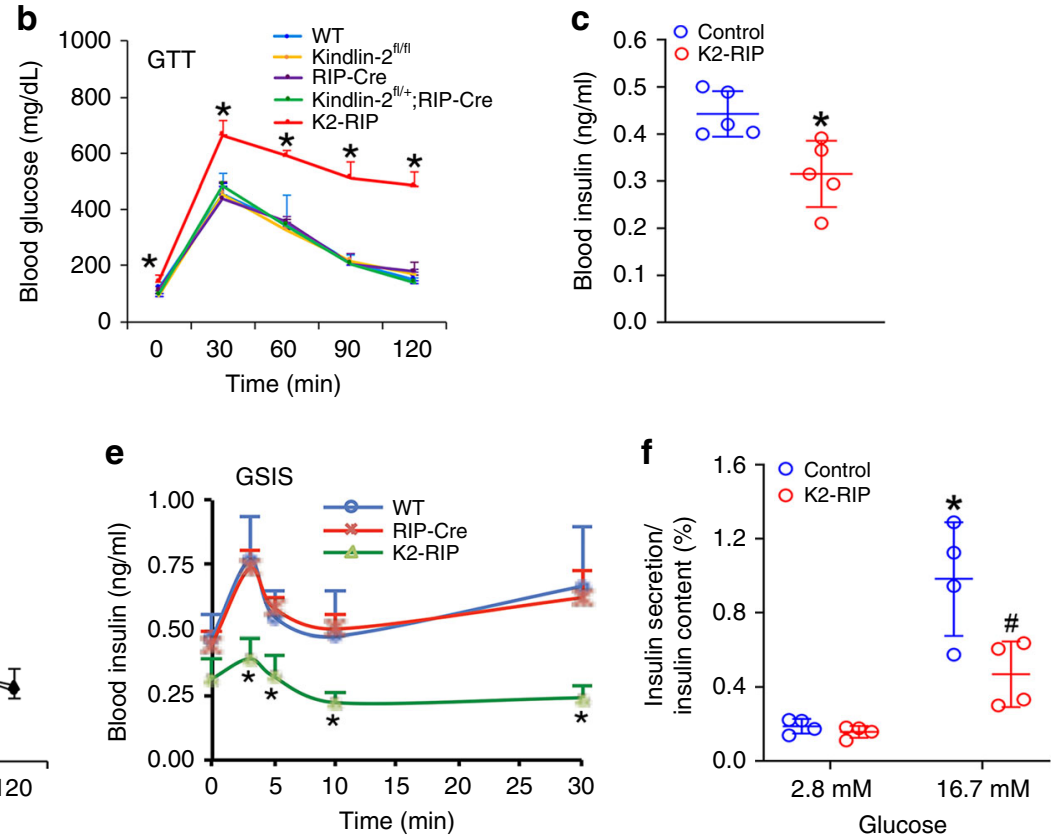

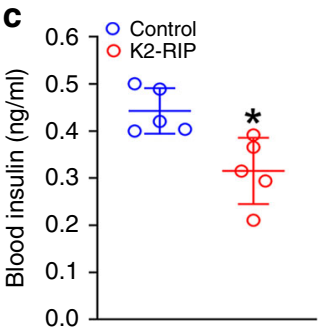

h

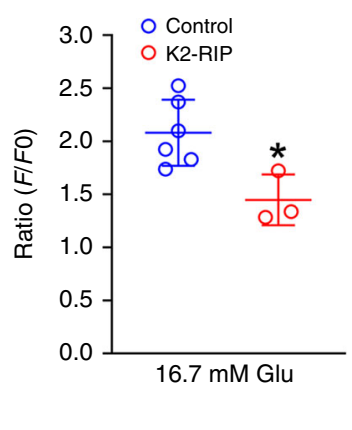

i

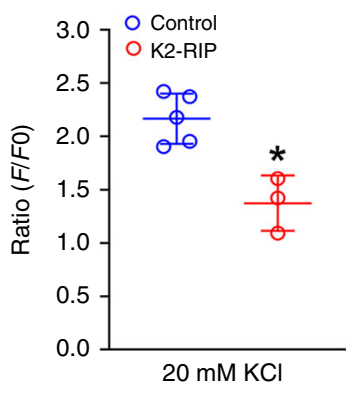

Fig. 2 Kindlin-2 loss causes severe diabetes-like phenotypes without affecting insulin sensitivity. a Fasting blood glucose level. Two-month-old male control (RIP-Cre) and K2-RIP mice were fasted overnight. ${ }^{\star} P<0.05$, versus control, $N=8$ for control, $N=7$ K2-RIP, $\mathbf{b}$ GTT. Mice treated as in a were given intraperitoneal injections of glucose ( $2 \mathrm{~g} / \mathrm{kg}$ body weight). ${ }^{\star} P<0.05$, versus control, $N=5$ for WT and $K 2-R I P, N=6$ for Kindlin- $2^{f / / f l}$, and $N=7$ for RIP-Cre and Kindlin- $2^{f l}+$; RIP-Cre. c Blood insulin level. Mice were treated as in a. ${ }^{\star} P<0.05$, versus control, $N=5$ mice per genotype. $\mathbf{d}$ ITT. Mice fasted (6-7 h) were intraperitoneally injected with a single dose of recombinant human insulin $\left(1 \mathrm{U} / \mathrm{kg}\right.$ body weight). ${ }^{\star} P<0.05$, versus control, $N=6$ for control, $N=8$ for K2-RIP. e In vivo GSIS. Mice treated as in a and intraperitoneally injected with glucose ( $2 \mathrm{~g} / \mathrm{kg}$ body weight). Blood insulin levels were measured by ELISA at $0,3,5,10$, and 30 min after glucose injection. ${ }^{\star} P<0.05$, versus control, $N=5$ for WT, $N=8$ for RIP-Cre and K2-RIP. f In vitro GSIS. Islets isolated from 2month-old male control K2-RIP mice were treated with 2.8 or $16.7 \mathrm{mM}$ glucose. Amounts of insulin in supernatant were measured by ELISA assay. Proteins were extracted and total insulin content was measured. Supernatant insulin was normalized to total insulin content. ${ }^{*} P<0.05$, versus $2.8 \mathrm{mM}$ glucose, $\# P<$ 0.05 , versus control. $\mathbf{g ~ C a}{ }^{2+}$ influx. Representative results from control and $K 2-R I P$ islets are provided. $N=15$ control islets, $N=20 \mathrm{~K} 2-R I P$ islets.

h Quantification of glucose $(16.7 \mathrm{mM})$ stimulation in control and mutant islets. $N=6$ islets for control, $N=3$ islets for $K 2-R I P,{ }^{\star} P<0.05$, versus control. $\mathbf{i}$ Quantification of $\mathrm{KCl}(20 \mathrm{mM})$ stimulation in control and mutant islets. $N=5$ islets for control, $N=3$ islets for $K 2-R I P$, ${ }^{\star} P<0.05$, versus control. Results are expressed as mean \pm standard deviation (s.d.) and Student's $t$ test was used in this figure. Source data for $\mathbf{a}-\mathbf{f}, \mathbf{h}, \mathbf{i}$ are provided as a Source Data file. 
(i.e., RIP-Cre), were viable and fertile and did not display marked glucose intolerance (Fig. 1b). These mice were used as control groups as specified in each experiment. A similar glucose intolerance was observed in 2-month-old female K2-RIP mice (Supplementary Fig. 1c). Kindlin-2 loss significantly reduced the level of fasting blood insulin $(P<0.05, K 2-R I P$ versus control, Student's $t$ test) (Fig. $2 \mathrm{c}$ and Supplementary Fig. 1d, e). We further performed insulin tolerance tests (ITT) and observed no significant difference in insulin sensitivity between the two genotypes (Fig. 2d and Supplementary Fig. 1f).

We next performed the GSIS assays to investigate whether Kindlin-2 regulates insulin secretion in mice. The blood insulin levels in K2-RIP mice and control littermates were measured at 3, 5,10 , and $30 \mathrm{~min}$ after a single-glucose injection $(2 \mathrm{~g} / \mathrm{kg}$ body weight). Both WT and RIP-Cre mice displayed an initial burst of insulin secretion within $5 \mathrm{~min}$ of glucose injection (the first-phase response), followed by a more sustained insulin secretion (the second-phase response). Both the first- and second-phase responses were markedly impaired in K2-RIP mice compared with WT and RIP-Cre littermates (Fig. 2e). To further establish the requirement for Kindlin-2 in insulin secretion, primary islets isolated from K2-RIP mice and control littermates (RIP-Cre) were treated with 2.8 or $16.7 \mathrm{mM}$ glucose in vitro, followed by measurements of insulin protein in the supernatant and in the whole cell extracts. Treatment of $16.7 \mathrm{mM}$ glucose stimulated a 5.2 -fold insulin secretion in control islets; this value was decreased to threefold in K2-RIP islets (Fig. 2f). Kindlin-2 loss impaired both the glucose- and $\mathrm{KCl}$-induced $\mathrm{Ca}^{2+}$ release from islets. After stimulation with a $16.7 \mathrm{mM}$ glucose load, $\mathrm{Ca}^{2+}$ release was significantly reduced in $K 2-R I P$ versus control islets (Fig. 2g, h). Similarly, the amplitude of $\mathrm{Ca}^{2+}$ transients stimulated by a $20 \mathrm{mM} \mathrm{KCl}$ load was also significantly decreased in K2-RIP islets compared with that of control islets (Fig. 2g, i).

Kindlin-2 loss reduces $\boldsymbol{\beta}$-cell proliferation and mass. We further measured the $\beta$-cell area/pancreatic area ratio and $\beta$-cell mass of K2-RIP and control littermates and demonstrated that both parameters were dramatically reduced in 1-week-old and 2month-old K2-RIP mice compared with those of their age- and sex-matched control littermates (Cre-RIP) (Fig. 3a, b). Notably, the magnitude of reductions in both parameters was larger in 2month-old mice than in 1-week-old K2-RIP mice (Fig. 3a, b), suggesting that impairment of $\beta$-cells becomes worse over time. Immunofluorescence (IF) staining of pancreatic sections using antibodies against Kindlin-2 and the proliferating cell nuclear antigen (Ki67) revealed that $\beta$-cell proliferation was reduced in 1week-old K2-RIP mice relative to that in control littermates (Fig. $3 c, d$ ). The reduction in $\beta$-cell mass could contribute to the diabetic phenotypes in K2-RIP mice.

Kindlin-2 loss activates GSK-3 $\beta$ and downregulates $\beta$-catenin. We further examined expression of cyclins D1 and D2, both required factors for $\beta$-cell proliferation ${ }^{13}$, by $\mathrm{qPCR}$ analysis and observed a reduced expression of both factors in 1-week-old K2RIP relative to control islets (Fig. 3e). In contrast, expression of the Wnt co-receptor Lrp5 was not altered in K2-RIP islets compared with control islets (Fig. 3e). We further examined expression of $\beta$-catenin, which regulates cyclin $D$ expression and $\beta$-cell proliferation and $\beta$-cell mass ${ }^{13}$ and observed that the levels of total and active $\beta$-catenin proteins were markedly reduced in K2RIP islets compared with those of control islets (Fig. 3g). GSK-3 phosphorylates $\beta$-catenin and targets its degradation. It is known that phosphorylation of the Ser9 residue in the GSK-3 $\beta$ molecule decreases its kinase activity ${ }^{37}$. Interestingly, the level of phosphoGSK-3 $\beta$ (Ser9), but not total GSK-3 $\beta$, was significantly reduced in
K2-RIP relative to that of control islets (Fig. $3 \mathrm{f}, \mathrm{g}$ ). This finding was confirmed by in situ immunohistochemistry (IHC) staining of pancreatic sections of the two genotypes (Fig. $3 \mathrm{~h}$ ). We further knocked down Kindlin-2 expression in primary human pancreatic islets using a lentiviral Kindlin-2 shRNA and found that Kindlin-2 knockdown dramatically reduced the levels of MafA, pGSK-3 $\beta$ (Ser9), and active $\beta$-catenin proteins (Fig. 3i, j). We also performed IHC staining of the pancreatic sections of 3-monthold diabetic $d b / d b$ male mice and sex- and age-matched control mice and observed that the immunoreactivity of Kindlin-2, MafA, active $\beta$-catenin, and $\mathrm{p}$-GSK- $3 \beta$ catenin was markedly reduced in $d b / d b$ islets relative to that of control islets (Fig. $3 \mathrm{k}$ ). Note: the 3 month-old $d b / d b$ male mice displayed a severe diabetic phenotype, as demonstrated by a dramatic increase in the level of fasting blood glucose and abnormal GTT result (Supplementary Fig. 2).

Kindlin-2 loss impairs pancreatic islet development. We further determined the islet composition by performing IF staining of pancreatic sections of E13.5, E15.5, E18.5, P0, and P7 control and K2-RIP mice using antibodies against insulin (for $\beta$-cells), glucagon (for $\alpha$-cells), or somatostatin (for $\delta$-cells). The results showed, as expected, that the murine islets were composed primarily of $\beta$-cells clustered in a central core, surrounded by smaller numbers of $\alpha$-cells and $\delta$-cells in the periphery (Fig. $4 \mathrm{a}$ ). The $\beta$ cells represented $55.8 \%, 65.7 \%$, and $73.4 \%$ in E18.5, P0, and P7 control islets, which were reduced to $48.8 \%, 52.7 \%$, and $56.4 \%$ in $K 2-R I P$ islets, respectively (Fig. $4 \mathrm{~b}-\mathrm{d})(P<0.05$, control versus $K 2-R I P$ for all three time points). The percentages of a-cells represented $26.9 \%, 16.5 \%$, and $18.7 \%$ in E18.5, P0, and P7 control islets, which were increased to $34.8 \%, 34.2 \%$, and $26.1 \%$ in $K 2$ RIP islets, respectively (Fig. $4 \mathrm{~b}-\mathrm{d})(P<0.05$, control versus $K 2-$ $R I P$ for all three time points). The percentages of $\delta$-cells in islets were much smaller than those of $\alpha$ - or $\beta$-cells and were not significantly different between the two genotypes (Fig. $4 \mathrm{~b}-\mathrm{d}$ ). Because islets were not completely formed in E13.5 and E15.5 mouse pancreatic tissue (Fig. 4a), we were unable to accurately define the borders of islets and did not determine the islet composition at those two time points.

Kindlin-2 activates insulin gene expression. We further investigated the potential role of Kindlin-2 in regulation of insulin expression. When compared with control islets, K2-RIP islets displayed reduced insulin, but not glucagon, expression, as demonstrated by IF (Fig. 5a) and qPCR analyses (Fig. 5b). In contrast, overexpression of Kindlin-2 increased expression of insulin protein and mRNA and activated the Ins1 promoter in INS- 1 cells, a rat pancreatic $\beta$-cell line (Supplementary Fig. 3). Because MafA is a master regulator of the insulin gene ${ }^{9}$, we determined the effect of Kindlin-2 deletion on its expression and found that MafA was strongly detected in the nuclei of control $\beta$ cells, which was dramatically reduced in K2-RIP $\beta$-cells (Fig. $5 \mathrm{c}$, top). In contrast, expression of $\mathrm{Pdx} 1$, which regulates insulin gene transcription, was not decreased in K2-RIP $\beta$-cells (Fig. $5 c$, bottom). Because Kindlin-2 loss did not reduce the MafA mRNA level (Fig. 5d), this regulation must involve a posttranscriptional mechanism. The Ins1 gene promoter contains a single MafAbinding site (C1) at $-119 /-132$ (Fig. 5e, top) that is essential for its $\beta$-cell-specific expression ${ }^{38,39}$. As expected, the overexpression of MafA in INS-1 cells stimulated Ins1 promoter activity and the introduction of a 4-bp point mutation into the $\mathrm{C} 1$ core sequence (from TACAGCTTCAGCC to TTACAGCTTCactc) abolished the MafA-dependent promoter activation (Fig. 5e, bottom). Kindlin- 2 activation of the Ins 1 promoter was lost in the absence of MafA expression (Fig. 5e, bottom) and the $\mathrm{C} 1$ site mutation 
a

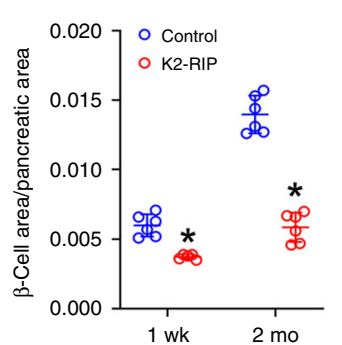

b

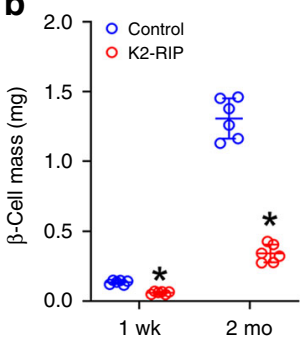

C

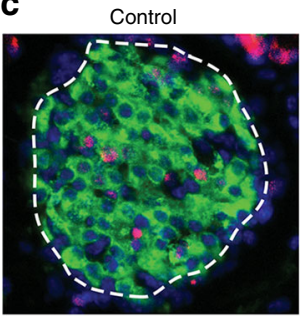

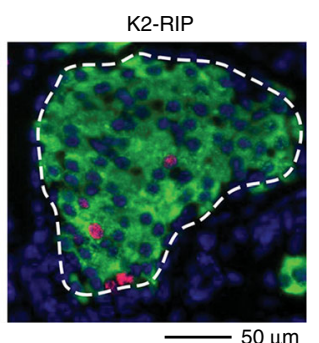
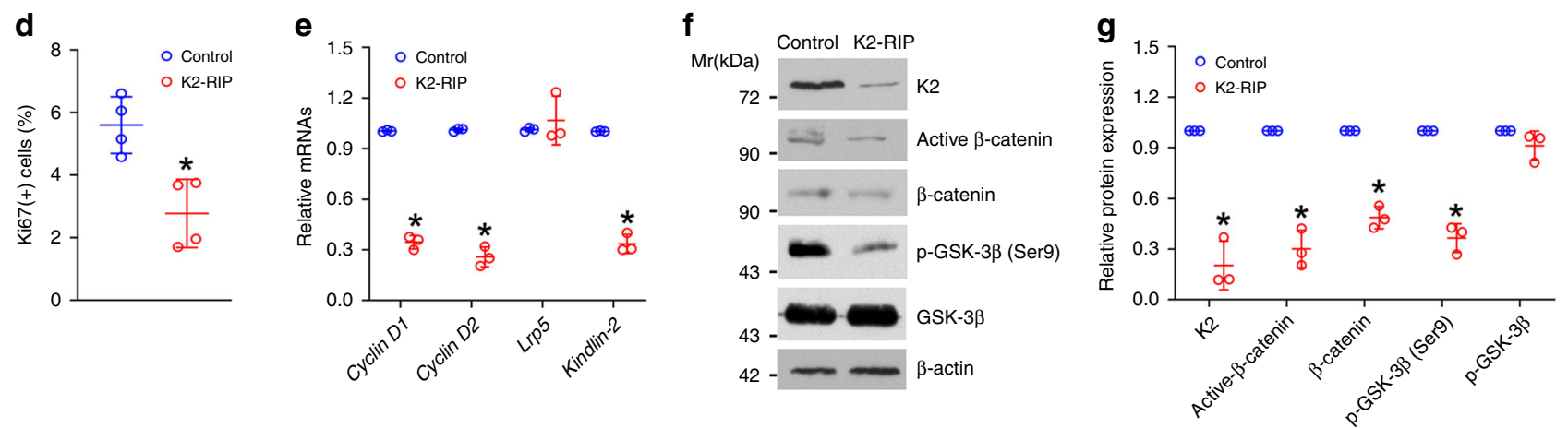

h

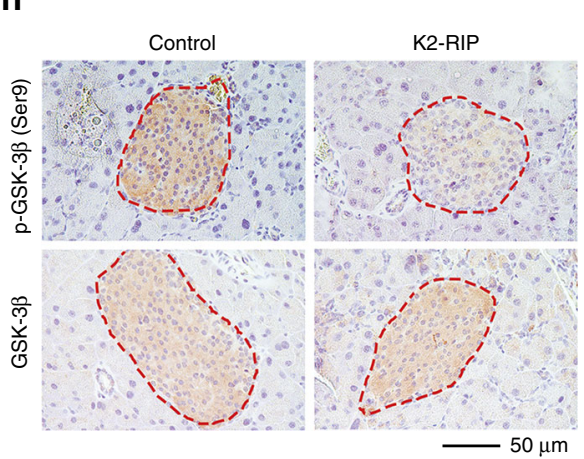

i

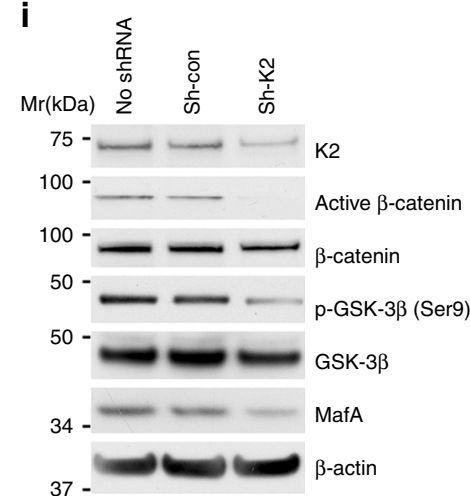

j

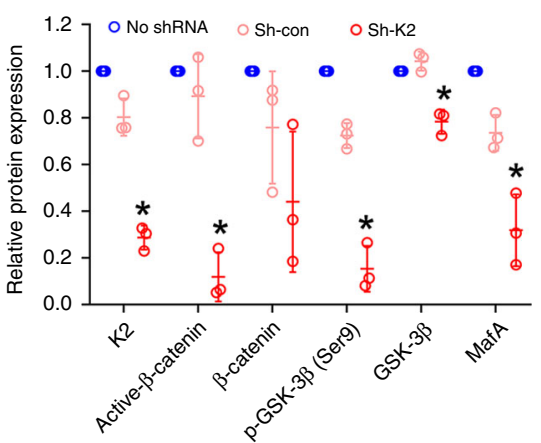

$\mathbf{k}$
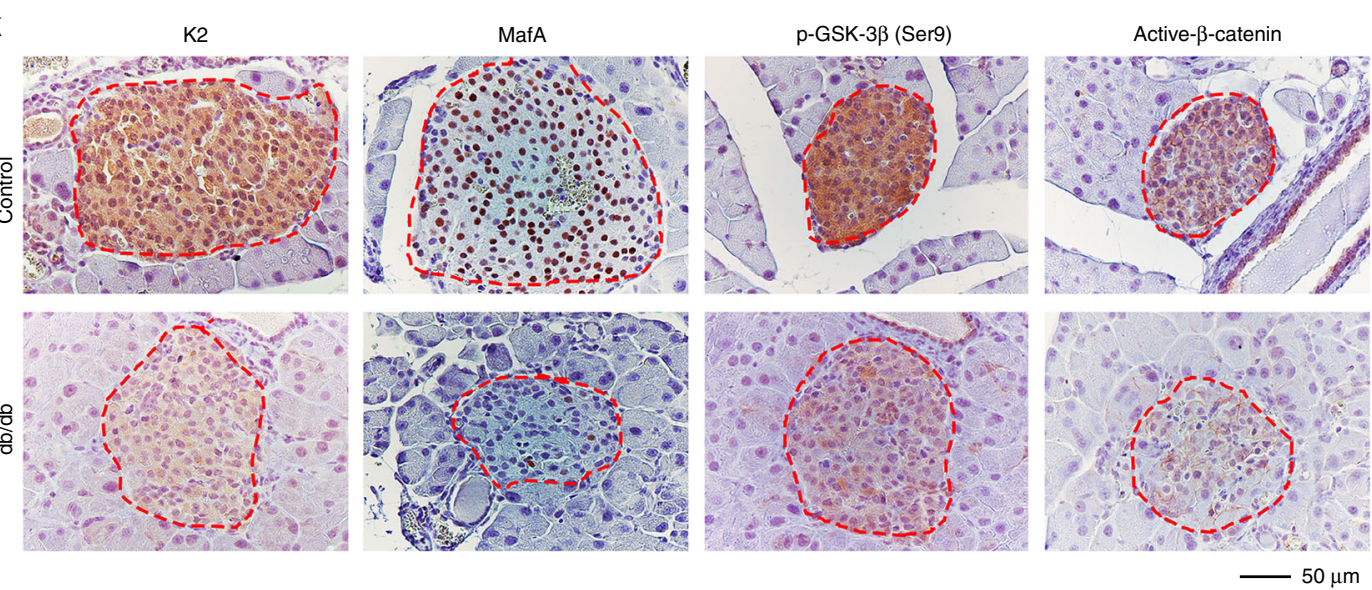

abolished the Kindlin-2 activation of the Ins1 promoter (Fig. 5e, bottom).

Kindlin-2 interacts with and stabilizes MafA protein. We next determined whether Kindlin-2 interacts with MafA by immunoprecipitation (IP) assays using extracts from COS-7 cells overexpressing Flag-Kindlin-2 and HA-MafA. Results showed that MafA protein was present in an anti-Kindlin-2 immunoprecipitate (Fig. 5f) and, vice versa, that Kindlin-2 protein was present in an anti-MafA immunoprecipitate (Fig. 5g). The interaction between the endogenous Kindlin-2 and MafA proteins was demonstrated by IP using extracts from rat pancreatic INS-1 cells (Fig. 5h, i). Results from the pulldown assays using purified GST-Kindlin-2 and glutathione Stransferase (GST)-MafA fusion proteins revealed a direct physical interaction between Kindlin-2 and MafA proteins (Fig. 5j, k). To identify domain(s) within the Kindlin-2 molecule 
Fig. 3 Kindlin-2 loss activates GSK-3 $\boldsymbol{\beta}$ and reduces $\boldsymbol{\beta}$-catenin expression and $\boldsymbol{\beta}$-cell proliferation and mass. a, $\mathbf{b}$ Pancreatic sections from 1-week- or 2 month-old male control (RIP-Cre) and K2-RIP mice were subjected to IF staining for insulin, followed by measurements of $\beta$-cell area/pancreatic area ratio (a) and $\beta$-cell mass (b). ${ }^{\star} P<0.05$, versus control, $N=5$ for 2 -month-old $K 2$-RIP in $\mathbf{a}, N=6$ for the remaining groups, Student's $t$ test. c, $\mathbf{d}$ Cell proliferation. Sections of 1-week-old control and mutant male pancreas were double stained with antibodies against insulin and Ki67 (c). Ki67-positive cells in islets were normalized to total insulin-positive cells in the same area (d). Around 444-816 $\beta$-cells (insulin-positive cells) per mouse were counted. $N=4$ mice per genotype. Scale bar, $20 \mu \mathrm{m} .{ }^{\star} P<0.05$, versus control, Student's $t$ test. e qPCR analyses. Total RNAs isolated from islets of 1-week-old K2-RIP and control littermates were subjected to qPCR analysis for the indicated genes. mRNA levels were normalized to Gapdh mRNA. Statistical analyses (Student's $t$ test) were performed using the average values of triplicates from three independent experiments. ${ }^{\star} P<0.05$, versus control. $\mathbf{f}$, $\mathbf{g}$ Western blot analysis. Protein extracts isolated from islets isolated from K2-RIP mice and control littermates (RIP-Cre) were subjected to Western blot analyses with indicated antibodies. Quantitative data from three independent experiments $(\mathbf{g}) .{ }^{\star} P<0.05$, versus control, Student's $t$ test. $\mathbf{h} I \mathrm{HC}$ staining of pancreatic sections with antibodies

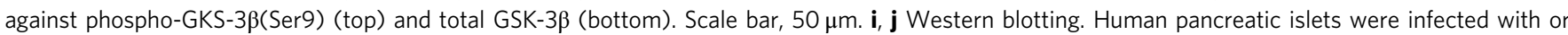
without Kindlin-2 shRNA (Sh-K2) or control (Sh-con) lentiviruses, followed by Western blot analyses with indicated antibodies. Quantitative data from three independent experiments (j). ${ }^{\star} P<0.05$, versus control (Sh-con), Student's $t$ test. $\mathbf{k} I H C$ staining of pancreatic sections of 3-month-old $d b / d b$ mice and age- and sex-matched C57BL/6 (control) mice with indicated antibodies. $N=3$ mice per genotypes. Scale bar, $50 \mu \mathrm{m}$. Results are expressed as mean \pm standard deviation. Source data for $\mathbf{a}, \mathbf{b}, \mathbf{d}-\mathbf{f}, \mathbf{i}, \mathbf{j}$ are provided as a Source Data file.

a
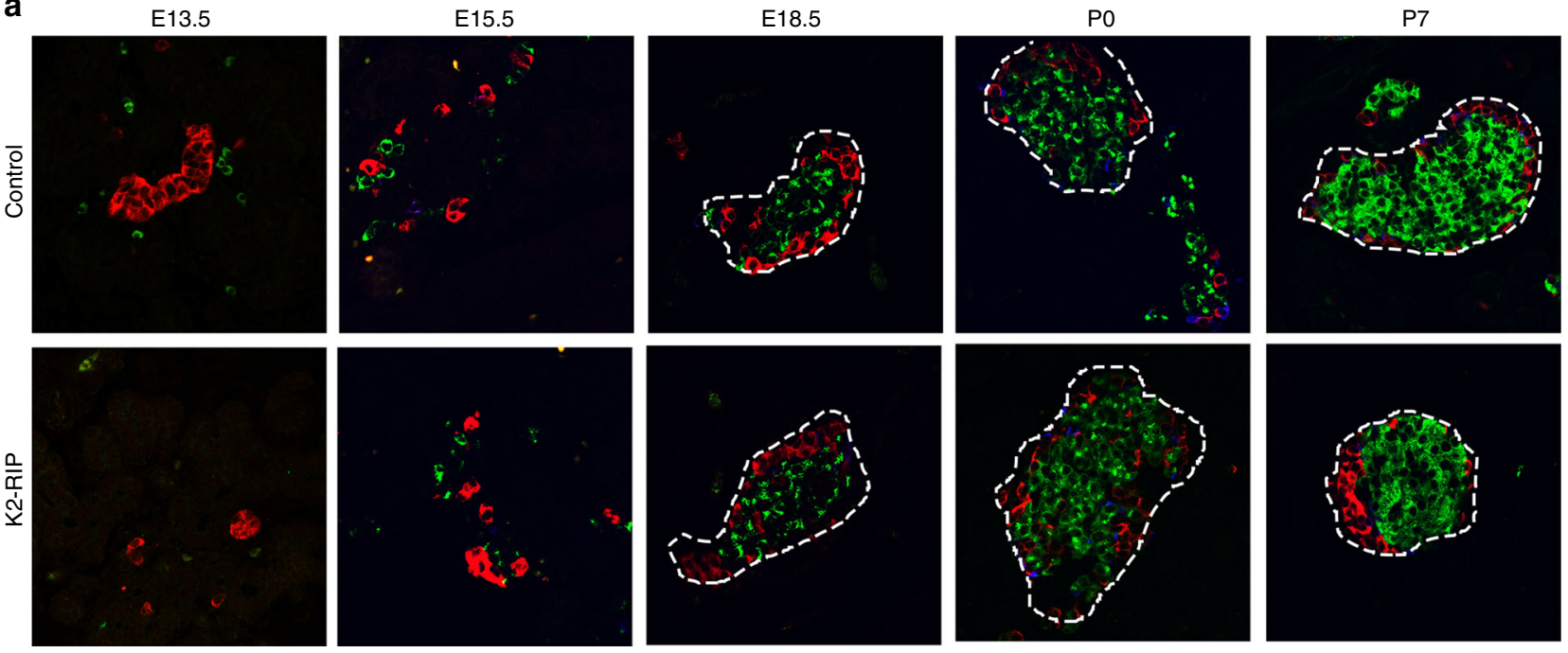

b

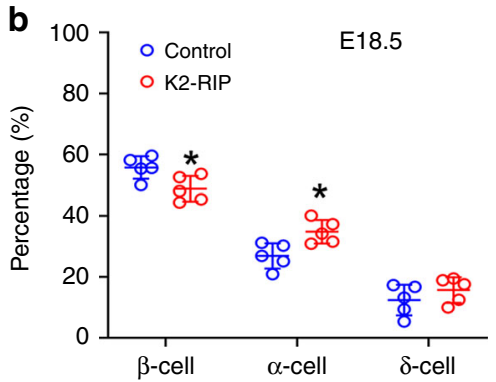

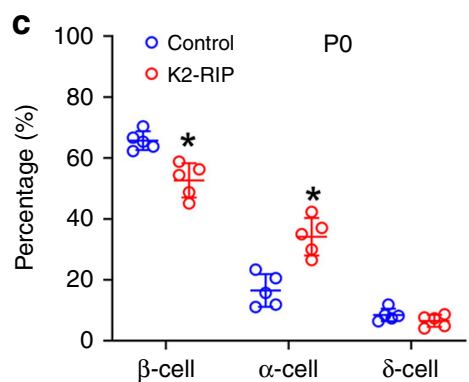

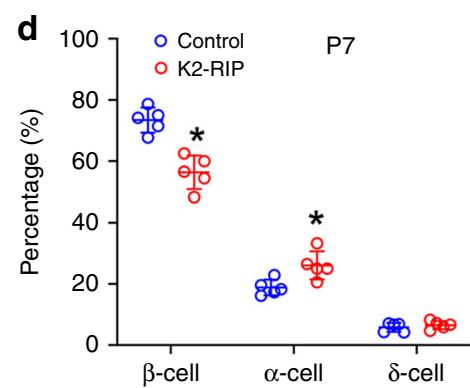

Fig. 4 Kindlin-2 loss impairs pancreatic islet development. a-d Immunofluorescence (IF) staining. E13.5, E15.5, E18.5, PO, and P7 pancreatic sections of control and K2-RIP mice were subjected to IF staining using antibodies against insulin (for $\beta$-cell), glucagon (for $\alpha$-cell), somatostatin (for $\delta$-cell), or DAPI (not shown). Pictures were captured (a) and the total number of $\alpha$-cells (red), $\beta$-cells (green), and $\delta$-cells (blue) counted and expressed as percentages of total cells in islets (b-d). We measured the islet cell composition from 22 to 34 islets per mouse. We analyzed islets from two sides (each slide had 3-5 pancreatic sections on it) from each mouse and obtained an average value from each slide. Thus, we obtained two data points for each mouse. For statistical analysis, we used the average value of those two data points for each mouse. $N=5$ mice per genotype at all time points. Scale bar, $50 \mu$ m. ${ }^{\star} P<$ 0.05 , versus control, Student's $t$ test. Because islets were not completely formed in E13.5 and E15.5 mouse pancreatic tissue, we were unable to accurately define the borders of the islets and did not determine the islet composition at those two time points. Results are expressed as mean \pm standard deviation. Source data for $\mathbf{b}-\mathbf{d}$ are provided as a Source Data file.

necessary for interaction with MafA, we generated several deletion mutants of Kindlin-2 (Fig. 5l) and tested for their ability to activate Ins 1 promoter in the presence of MafA and observed a major drop in promoter activation when the $\mathrm{C}$ terminus of Kindlin-2 (aa 570 to aa 680) was deleted (Fig. $5 \mathrm{~m}$ ). Further deletion to aa 239 did not exacerbate the activation of the Ins 1 promoter. The Kindlin-2 mutant with the N-terminal aa 1-569 deletion effectively activated the Ins 1 promoter. Consistent with this functional data, deletions of Kindlin-2 from aa 239 or 570 to aa 680 completely abolished the formation of the Kindlin-2-MafA complex (Fig. 5n). Likewise, deletion of aa 1 to aa 569 did not abrogate the interaction 
a

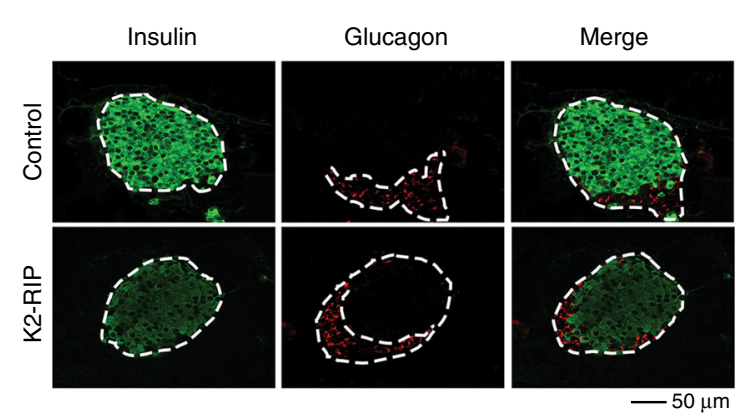

b

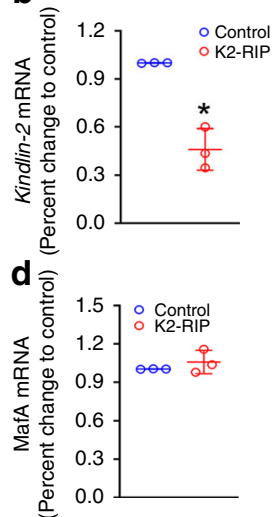

C

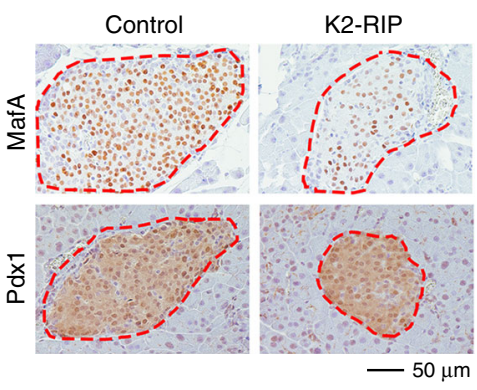

e
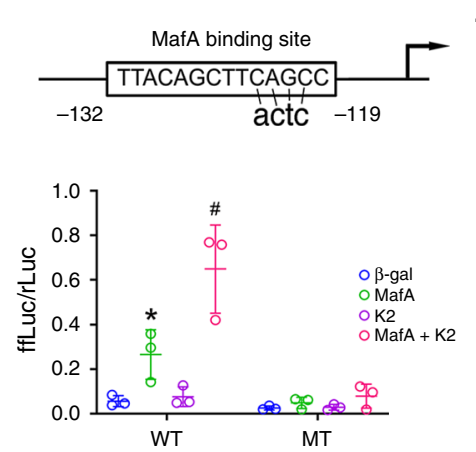

f IP: IgG HA Input $\operatorname{Mr}(\mathrm{kDa}) \quad-\quad \mathrm{IB}: \mathrm{M} 2$
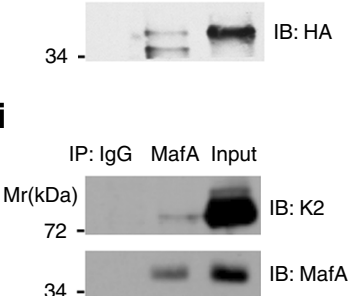

g

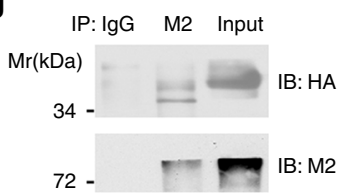

i

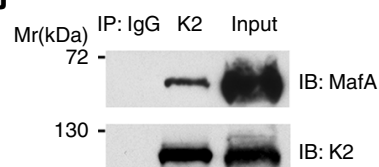

h

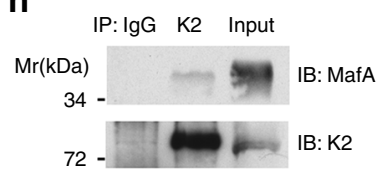

k

$\operatorname{Mr}(\mathrm{kDa})$ IP: IgG MafA Input

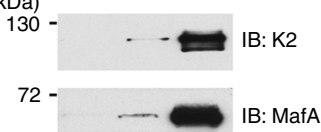

I

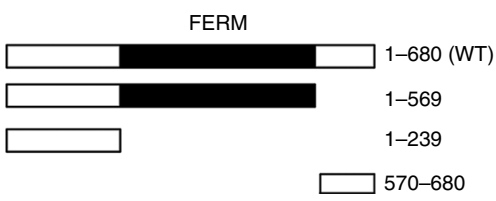

m

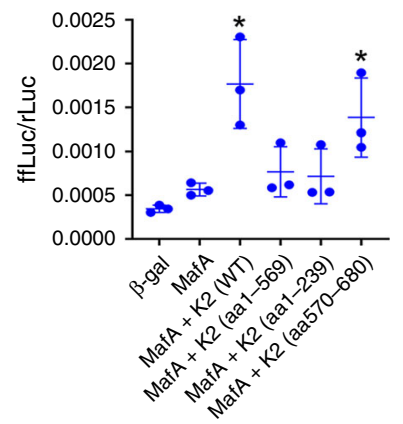

o

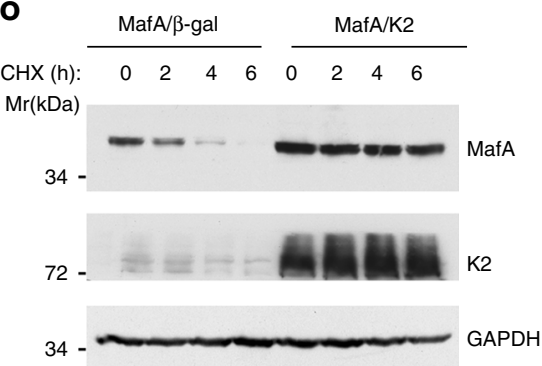

n
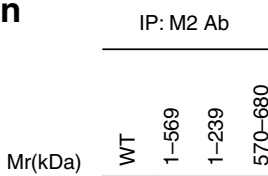

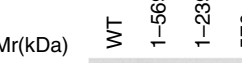

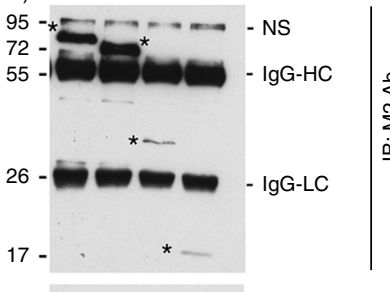

34 -

IB: MafA Ab

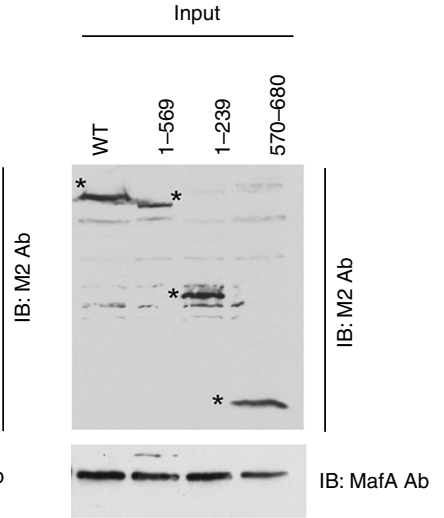

between Kindlin-2 and MafA. Together, these data establish that the aa 570-680 region of Kindlin-2 is required for its interaction with MafA. We next performed cycloheximide (a protein synthesis inhibitor) experiments and demonstrated that overexpression of Kindlin-2 markedly increased MafA stability (Fig. 5o). Western blot analysis using nuclear and cytoplasmic extracts showed that Kindlin-2 protein existed in the nuclei of INS- 1 cells (Fig. 5p).

Kindlin-2 functions independent of $\beta$ integrin activation. Because the aa $570-680$ region of Kindlin- 2 contains a $\beta$ integrin- 
Fig. 5 Kindlin-2 interacts with and stabilizes MafA to activate insulin gene expression. a IF staining. Pancreatic sections of 2-month-old male control (RIP-Cre) and K2-RIP mice were stained with the indicated antibodies. Scale bar, $50 \mu \mathrm{m}$. b qPCR analysis. Total RNA isolated from 2-month-old control and K2-RIP islets was subjected to qPCR analysis. Insulin mRNA was normalized to Gapdh mRNA. ${ }^{\star} P<0.05$, versus control. c IHC. Sections of 2-month-old pancreas were stained with the indicated antibodies. Scale bar, $50 \mu \mathrm{m} . N=5$ per genotype. $\mathbf{d}$ qPCR analysis. Total RNA from $\mathbf{b}$ was used. e (top) Schematic representation of the rat Ins1 gene promoter. e (bottom) COS-7 cells were transfected with p460rlns1-luc or p460rIns1C1mt-luc, pRL-SV40, and expression plasmids for $\beta$-gal, Kindlin-2, MafA, or Kindlin-2 plus MafA. After $48 \mathrm{~h}$, cells were harvested for dual-luciferase assays. ${ }^{\star} P<0.05$, versus $\beta$-gal, $\# P<0.05$, versus MafA. f-k IP assay. Whole cell extracts from COS-7 cells overexpressing pCMV/Flag-Kindlin-2 and pCMV/HA-MafA (f, $\mathbf{g}$ ) or INS-1 cells $(\mathbf{h}, \mathbf{i})$ or a mixture of GST-MafA and GST-Kindlin-2 (j, $\mathbf{k})$ were immunoprecipitated with the indicated antibodies, followed by Western blot analyses using the indicated antibodies. I A schematic showing the domain structure of Kindlin-2 and the deletion mutants. $\mathbf{m}$ COS-7 cells were co-transfected with p460rIns1-luc, pRL-SV40 (for normalization), pCMV/MafA, and pCMV vectors expressing wild type (WT) or various deletion Kindlin-2 mutants, followed by dual-luciferase assays. ${ }^{\star} P<0.05$, versus $\mathrm{pCMV} / \beta$-gal. $\mathbf{n} \mathrm{IP}$ assay. COS-7 cells were transfected with MafA expression plasmids and various FlagKindlin-2 deletion mutant expression plasmids. After $48 \mathrm{~h}$, whole cell extracts were prepared and immunoprecipitated with $\mathrm{M} 2$ antibody, followed by Western blot analysis using M2 (top) or MafA antibody (bottom) (left panel). o COS-7 cells were transfected with a MafA expression plasmid with or without Kindlin-2 overexpression and treated with $10 \mu \mathrm{g} / \mathrm{ml}$ cycloheximide, followed by Western blotting at the indicated times. p Western blot analysis. Cytoplasmic (CE) and nuclear extracts (NE) from INS-1 cells subjected to Western blotting for Kindlin-2, MafA, and tubulin (a cytoplasmic protein). Results are expressed as mean \pm standard deviation and Student's $t$ test was used in this figure. Source data for $\mathbf{b}, \mathbf{d}-\mathbf{k}, \mathbf{m}-\mathbf{p}$ are provided as a Source Data file.

binding site that mediates $\beta$ integrin activation ${ }^{40,41}$, we next investigated whether Kindlin-2 regulation of MafA and insulin expression involves $\beta$ integrin binding and activation. We determined the ability of wild-type Kindlin-2 (K2-WT) and an integrin-binding defective Kindlin-2 (K2-QW) to activate the Ins 1 promoter in the presence or absence of MafA in COS-7 cells. The results showed that K2-WT and K2-QW similarly activated Ins 1 promoter activity in a MafA-dependent manner (Supplementary Fig. 4a). Furthermore, both K2-WT and K2-QW could interact with and upregulate MafA (Supplementary Fig. 4b, c). Likewise, both K2-WT and K2-QW could activate endogenous Ins 1 mRNA expression in INS-1 cells (Supplementary Fig. 4d). Collectively, these results demonstrate that Kindlin-2 modulation of MafA and insulin expression is not dependent on its ability to activate $\beta$ integrin.

Kindlin-2 loss in adult mice causes diabetic phenotypes. We further investigated the role of Kindlin- 2 in $\beta$-cells in adult animals. To do this, we utilized mice bearing conditional alleles of Kindlin-2 (Kindlin-2 $2^{f / f l}$ ) and a MIP-Cre/ERT transgene, which expresses tamoxifen (TM)-inducible Cre recombinase under the control of mouse insulin gene 1 promoter $(M I P)$ in $\beta$-cells. These mice (3-month-old) were treated with five daily injections of TM $(100 \mathrm{mg} / \mathrm{kg}$ body weight) to delete Kindlin-2 expression in $\beta$-cells (hereafter referred to as K2f/f; MIPCreERT) (Fig. 6a). Consistent with results from K2-RIP mice, the expression of Kindlin-2 and MafA proteins was markedly reduced in islets of as $\mathrm{K} 2 \mathrm{f} / \mathrm{f}$; MIPCreERT mice relative to that of control littermates, as demonstrated by IHC (Fig. 6b). At day 30 after TM injections, $K 2^{f / f}$; MIPCreERT mice displayed obvious abnormalities in GTT (Fig. 6c) and GSIS (Fig. 6d). A similar defect in GTT was observed in female K2ff; MIPCreERT mice (Supplementary Fig. 5). K2/f; MIPCreERT mice displayed a slightly steeper slope than control mice at 30 and $120 \mathrm{~min}$, but not 60 and $90 \mathrm{~min}$, after insulin injection, suggesting a slight reduction in insulin sensitivity in these animals (Fig. 6e). Furthermore, K2f/f; MIPCreERT mice displayed significant reductions in the $\beta$-cell area/pancreatic area ratio (Fig. 6f) and $\beta$-cell mass (Fig. 6g) and an increase in $\beta$ cell apoptosis (Fig. 6h). $\beta$-Cell proliferation was minimal and was not altered in adult $K 2^{f / f}$; MIPCreERT mice relative to that of control littermates (Fig. 6i).

$\boldsymbol{\beta}$-Catenin activation reverses the phenotypes of K2-RIP mice. We additionally investigated whether genetic activation of $\beta$ catenin in $\beta$-cells reverses the diabetic phenotypes induced by Kindlin-2 loss. To do this, we bred K2fff; MIPCreERT with $\beta$ catenin (ex3) fl/fl mice and generated K2f/f; MIPCreERT; $\beta$-catenin $(\text { ex } 3)^{f l /+}$ (hereafter referred to as K2f/f; MIPCreERT; $\beta$-cat $(\text { ex } 3)^{f l+}+$ ) mice. In these mice, a dominant active form of $\beta$-catenin that lacks the GSK phosphorylation sites $(\beta$-catenin (ex3)) was expressed in $\beta$-cells in the $K 2^{f / f}$; MIPCreERT genetic background. At 1 month of age, K2f/f; MIPCreERT; $\beta$-cat $(\text { ex } 3)^{f l /+}$ mice and control littermates were treated with TM as indicated in Fig. 7a. Western blotting detected the presence of the $\beta$-catenin (ex3) protein in islets of the K2f/f; MIPCreERT; $\beta$-cat $(\text { ex3 })^{f l /+}$ mice treated with TM, but not in Cre-negative control mice treated with TM (Fig. 7b). The activation of $\beta$-catenin significantly restored the defective GTT in K2f/f; MIPCreERT mice (Fig. $7 \mathrm{c}$ ) $\left(P<0.05, K 2^{f / f} ;\right.$ MIP-CreERT versus K2f/f; MIP-CreERT; $\beta$-cat $\left.(\text { ex } 3)^{f /+}\right)$. Furthermore, the activation of $\beta$-catenin largely restored the abnormalities in GSIS and $\beta$-cell mass in $K 2$ f/f; MIPCreERT mice to levels comparable with those in the control group (Fig. 7d, e) without markedly affecting insulin sensitivity (Fig. 7f). Finally, primary islets were isolated from each group and treated with glucose or $\mathrm{KCl}$ in vitro. Results showed that treatment of $16.7 \mathrm{mM}$ glucose induced a 6.5 -fold insulin secretion in control islets; this value was decreased to 2.9 -fold in $\mathrm{K} 2 \mathrm{fl} / \mathrm{fl}$; $\mathrm{MIP}$ CreERT islets (Fig. $7 \mathrm{~g}$ ). Activation of $\beta$-catenin in $\beta$-cells restored the decrease in insulin secretion induced by Kindlin-2 loss. Likewise, treatment of $20 \mathrm{mM} \mathrm{KCl}$ stimulated a 7.7-fold insulin secretion in control islets; which was reduced to 3.5-fold in $\mathrm{K} 2 \mathrm{fl} /$ $\mathrm{fl}$; MIP-CreERT islets. Again, activation of $\beta$-catenin in $\beta$-cells completely restored the defective insulin secretion in mutant cells. The results revealed that the glucose- and KCl-induced insulin secretion was significantly decreased in $K 2^{f / f}$; MIP-CreERT islets compared with that of MIP-CreERT islets; this reduction was completely restored in $K 2^{f / f} ; M I P-C r e E R T ; \beta$-cat (ex3) $f l /+$ islets compared with that of MIP-CreERT islets (Fig. $7 \mathrm{~g}$ ). Please note: islets used in these experiments displayed excellent cell viability (Supplementary Fig. 6). Dead cells were scarcely observed in islets of the three genotypes and the morphology of the islets was intact.

\section{Discussion}

The results of our present study establish that Kindlin-2 plays a critical role in regulation of glucose homeostasis during development and homeostasis. In the absence of $\beta$-cell Kindlin-2, mice develop high fasting glycemia and fail to properly respond to hyperglycemia. The hyperglycemia seen following Kindlin-2 loss is driven by impairments in GSIS, insulin expression, and $\beta$-cell mass, but not by impacting peripheral insulin resistance. Our findings are of broad significance because $\beta$-cell failure induced by combination of $\beta$-cell loss and impaired insulin secretion from remaining $\beta$-cells is a key pathologic basis for diabetes. 
a

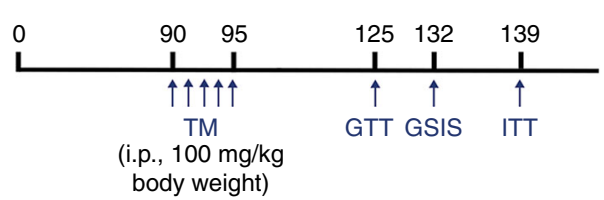

b

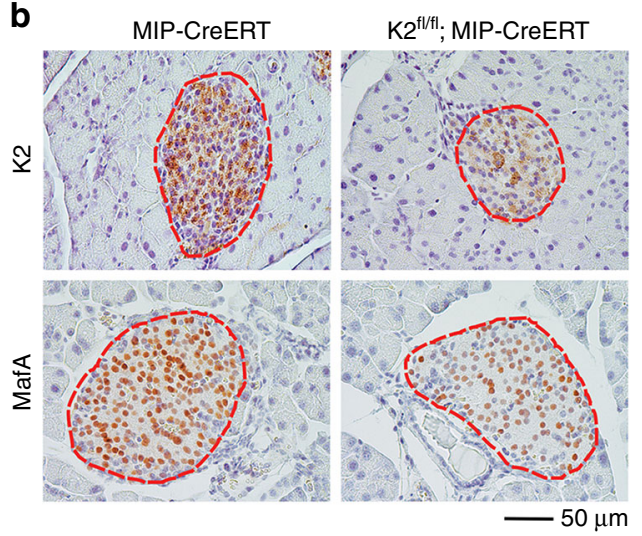

c

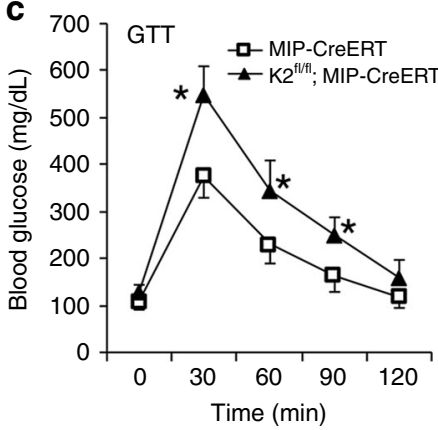

e

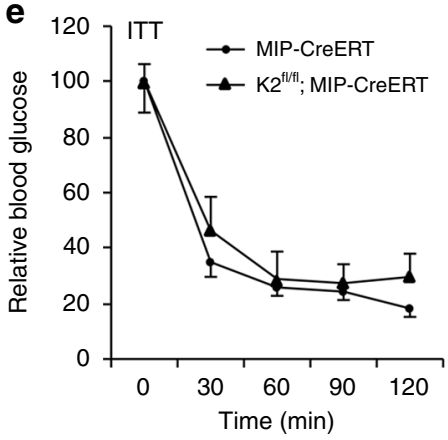

d

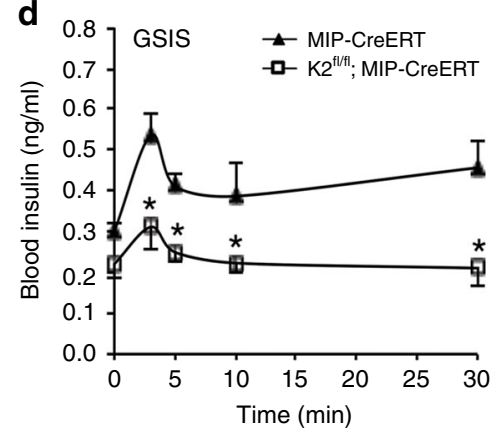

f

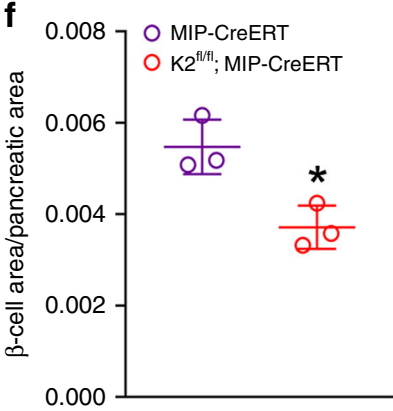

g

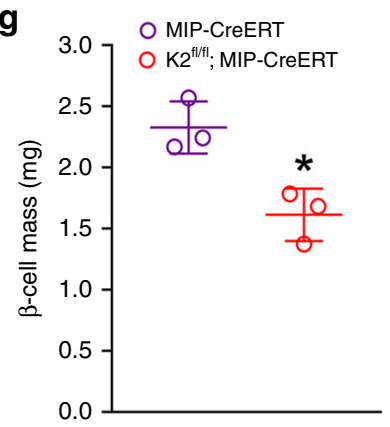

h

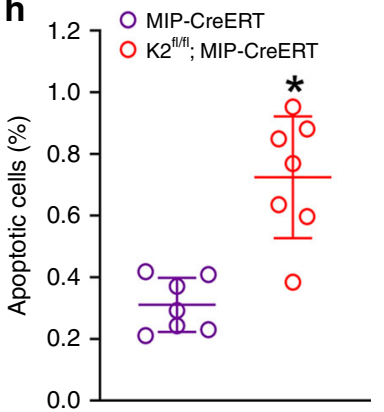

i

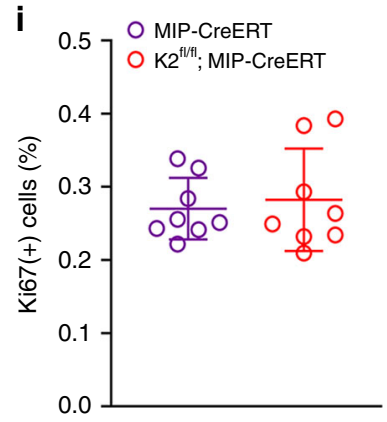

Fig. $\mathbf{6}$ Inducible deletion of $\boldsymbol{\beta}$-cell Kindlin-2 in adult mice leads to diabetes-like phenotypes. a Tamoxifen (TM) injection. $\mathbf{b} I H C$. Three-month-old male K2f/f; MIPCreERT and control (MIP-CreERT) mice were treated with TM as described in a. After 30 days, pancreatic sections were stained with antibodies against Kindlin-2 or MafA. Scale bar, $50 \mu \mathrm{m}$. c GTT. Mice were treated with TM as described in a. Thirty days after the TM injection, mice were fasted overnight, and GTT assays were performed. ${ }^{\star} P<0.05$, versus control, $N=10$ for control, $N=7$ for K2f/f; MIPCreERT, Student's $t$ test. d Glucose stimulated insulin secretion (GSIS). Mice were treated with TM as in $\mathbf{a}$. After 37 days, mice were fasted overnight, and GSIS assays were performed. ${ }^{\star} P<0.05$, versus control, $N=6$ for both genotypes, Student's $t$ test. e Insulin tolerance test (ITT). Mice were treated with TM as in a. After 44 days, mice were fasted for 6-7 h, and ITT assays were performed. $N=5$ for control, $N=4$ for $K 2 f / f ; M I P C r e E R T$. f, $\mathbf{g} \beta$-Cell area/pancreatic area ratio and $\beta$-cell mass. Mice were treated as in a. After 30 days, pancreatic sections were subjected to IHC staining for insulin, followed by measurements of $\beta$-cell area/pancreatic area ratio (f) and $\beta$-cell mass $(\mathbf{g}){ }^{\star} P<0.05$, versus control, $N=3$ per genotype. $\mathbf{h}$ Cell apoptosis. Mice were treated with TM as in a. After 30 days, pancreatic sections were subjected to insulin and TUNEL staining. Around 300-500 $\beta$-cells (insulin-positive cells) per mouse were counted. $N=7$ mice per group. ${ }^{\star} P$ $<0.05$, versus control, Student's $t$ test. i Cell proliferation. Mice were treated with TM as in $\mathbf{a}$. After 30 days, pancreatic sections were double stained with antibodies against insulin and Ki67. Ki67-positive cells in islets were normalized to total insulin-positive cells in the same area (i). Around 300-500 $\beta$-cells per mouse were counted. $N=8$ per genotype. Results are expressed as mean \pm standard deviation. Source data for c-i are provided as a Source Data file.

In the present study, we demonstrate that Kindlin-2 regulates $\beta$-cell function and homeostasis by modulating, at least in part, $\beta$-catenin. GSK-3 $\beta$ is a key player in the canonical pathway that regulates the phosphorylation and degradation of $\beta$-catenin. Interestingly, we find that Kindlin-2 loss activates GSK-3 $\beta$ by reducing phosphorylation of a negative-regulatory site (Ser9) via undefined mechanism(s), which reduces $\beta$ catenin stability and accelerates its degradation in $\beta$-cells. The reduced level of $\beta$-catenin protein reduces $\beta$-cell proliferation and expansion and $\beta$-cell mass ${ }^{13}$. This notion is further supported by results from our in vivo rescue experiments in that genetic activation of $\beta$-catenin largely restores the defective GTT, GSIS, and $\beta$-cell mass induced by the loss of Kindlin-2.
Interestingly, $\mathrm{Yu}$ et al. reported that Kindlin-2 physically interacted with $\beta$-catenin and increased its protein stability to enhance Wnt signaling and promote tumor invasion ${ }^{42}$. Similarly, Qu et al. showed that Kindlin-2 interacted with $\beta$-catenin and YB-1 to enhance EGFR transcription during glioma progression ${ }^{43}$. A more recent study by Lin et al. showed that Kindlin-2 promoted hepatocellular carcinoma invasion and metastasis by increasing $\mathrm{Wnt} / \beta$-catenin signaling ${ }^{44}$. While these in vitro studies suggest a role of the Kindlin-2- $\beta$-catenin interaction in regulation of cell functions, in the present study we provide the first in vivo evidence that both factors function in the same genetic pathway in $\beta$-cells to regulate glucose homeostasis in mice. 
a

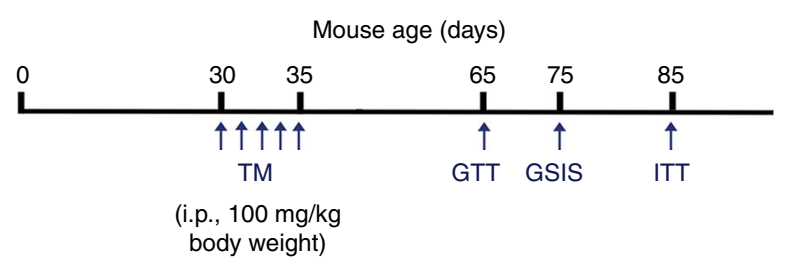

b

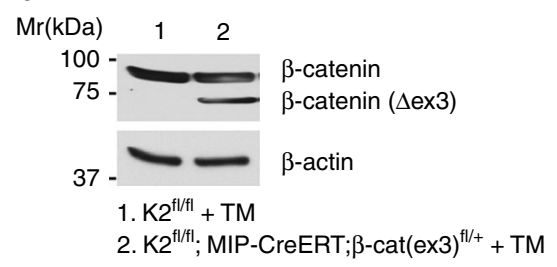

C

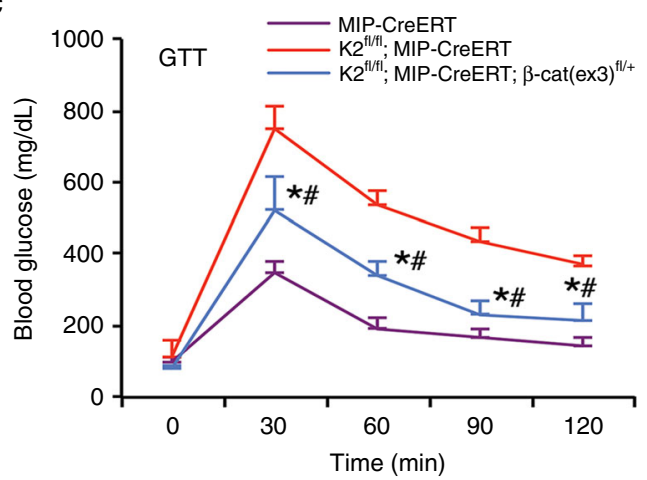

d

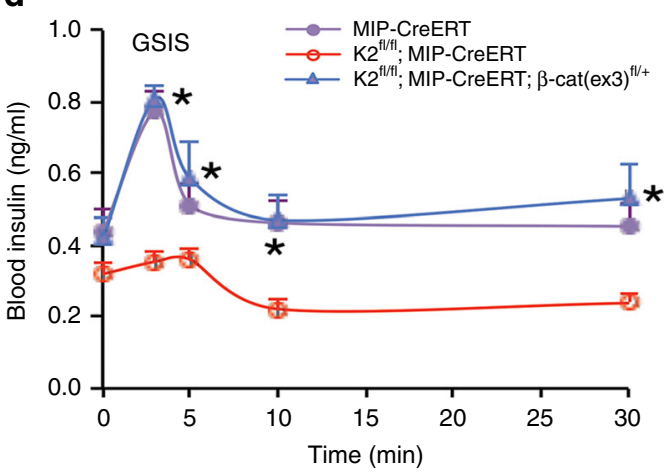

e

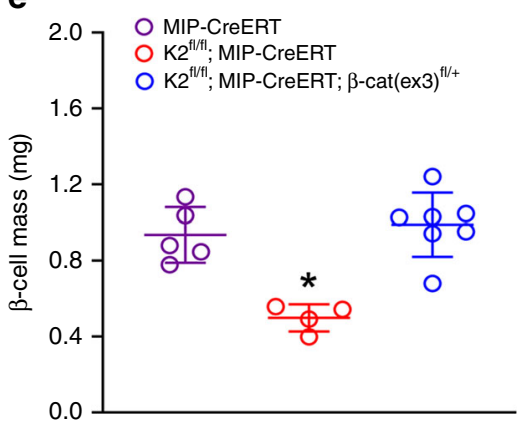

f

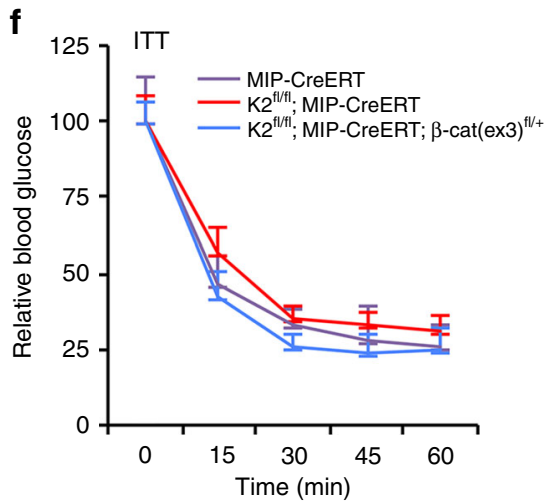

h

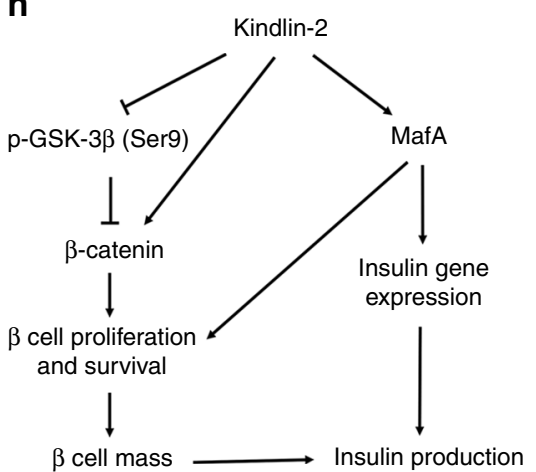

The severe glucose intolerance of the K2-RIP animals is in part a consequence of impairment of insulin release from the pancreatic $\beta$-cells. Both the first- and second-phase insulin release stimulated by glucose is markedly reduced in the mutant animals. Multiple mechanisms could be involved. Our in vitro study using physiologically relevant primary islets reveals that Kindlin-2 loss impairs the $\mathrm{Ca}^{2+}$ influx in $\beta$-cells, a critical step for the exocytosis of insulin secretory vesicles. It is likely Kindlin-2 regulates the insulin secretion process through its ability to modulate cytoskeletal remodeling and integrin-ECM interactions, which are all actively involved in modulating insulin granule trafficking and secretion ${ }^{45-50}$. Furthermore, Kindlin-2 signaling maintains a normal $\beta$-cell mass via its pro-proliferative and/or pro-survival effects on $\beta$-cells. Reduced $\beta$-cell mass additionally reduces both the insulin production and secretion in the K2-RIP mice. $\beta$-Cell deficiency plays an important role in the pathogenesis of both type 1 and type $2 \mathrm{DM}$. Therefore, restoration or replacement of $\beta$ cell function is a long-term goal for the treatment. The Kindlin-2 signaling pathway in $\beta$-cells provides a potential therapeutic target for achieving this goal.

In the present study, we provide intriguing and convincing evidence that Kindlin-2 activates insulin expression by interacting with and modulating MafA, a master regulator of insulin gene transcription. First, that loss of Kindlin-2 drastically reduces the level of MafA protein without affecting its mRNA in $\beta$-cells suggests a posttranscriptional mechanism. Second, Kindlin-2 
Fig. 7 Genetic activation of $\boldsymbol{\beta}$-cell $\boldsymbol{\beta}$-catenin restores the diabetes-like phenotype induced by Kindlin-2 loss. a Tamoxifen (TM) injection. $\mathbf{b}$ Western blotting. Protein extracts from isolated islets of indicated genotypes treated with TM as described in a were subjected to Western blotting. c GTT. Mice were treated with TM as described in a and fasted overnight. ${ }^{\star} P<0.05$, versus MIP-CreERT (control), $\# P<0.05$, versus $K 2^{f / f} ; M I P-C r e E R T, N=6$ for $M I P$ CreERT, N = 4 for K2fff; MIP-CreERT and K2fff; MIP-CreERT; $\beta$-cat (ex $)^{f / /+}$, Student's $t$ test. d GSIS. Mice with indicated genotypes were treated with TM as described in a and fasted overnight. ${ }^{\star} P<0.05$, versus $K 2^{f / f} ;$ MIP-CreERT, $N=5$ for MIP-CreERT, N =4 for K2f/f; MIP-CreERT, and N=6 for K2f/f; MIP-CreERT; $\beta$-cat $(e x)^{f l} /+$. Student's $t$ test. e $\beta$-cell mass. After the ITT experiments, pancreatic sections were subjected to IHC staining for insulin, followed by measurements of $\beta$-cell mass. ${ }^{\star} P<0.05$, versus MIP-CreERT (control), $\# P<0.05$, versus $K 2^{f / f}$; MIP-CreERT. $N=5$ for MIP-CreERT, $N=4$ for K2f/f; MIPCreERT, and $N=7$ for $K 2^{f / f} ;$ MIP-CreERT; $\beta$-cat (ex $f^{f l /+}$. Student's $t$ test. $\mathbf{f I T T}$. Mice with indicated genotypes were treated with TM as described in a and fasted $(6-7 \mathrm{~h})$, followed by performance of ITT assays. $N=7$ for control, $N=4$ for $K 2^{f / f} ;$ MIP-CreERT and K2f/f; MIP-CreERT; $\beta$-cat (ex)fl/ + . $\mathbf{g}$ Insulin secretion. One-month-old male MIP-CreERT, K2f/f; MIP-CreERT and $K 2^{f / f} ;$ MIP-CreERT; $\beta$-cat (ex $)^{f / /}+$ mice were injected with TM as described in a. One month after the last TM injection, islets were isolated from each group and treated with 2.8 or $16.7 \mathrm{mM}$ glucose or $20 \mathrm{mM} \mathrm{KCl}$. Amounts of insulin in supernatant were measured by enzyme-linked immunosorbent assay (ELISA). Insulin secretion was measured as described in Fig. $2 f$. ${ }^{\star} P<0.05$, versus control (MIP-CreERT), Student's $t$ test. Results are expressed as mean \pm standard deviation. $\mathbf{h}$ A working model for Kindlin- 2 regulation of $\beta$ cell function. Source data for $\mathbf{b}-\mathbf{g}$ are provided as a Source Data file.

activation of the insulin gene promoter is highly dependent on the presence of MafA. Third, Kindlin-2, through its C-terminal region, interacts with MafA and increases its protein stability. The nuclear localization of Kindlin-2 facilitates its interaction with and upregulation of MafA. A putative nuclear localization signal was described in the Kindlin-2 molecule (amino acids 55-72) ${ }^{51}$. Furthermore, Kindlin-2 protein is present in nuclei of the ADTC5 chondrocytes $^{34}$ and the INS- 1 pancreatic $\beta$ cells as demonstrated in this study. Further studies are necessary to define the molecular mechanism(s) responsible for Kindlin-2 nuclear localization. It is known that MafA is phosphorylated at multiple sites by GSK-3 $\beta$. The phosphorylation of Ser65 in MafA is necessary for the sequential action of GSK-3 $\beta$ on the other sites, acting as the first step for degradation of MafA protein under low-glucose conditions ${ }^{52-54}$. Results from the present study show that Kindlin-2 loss activates GSK-3 $\beta$ by reducing its phosphorylation at Ser9. Thus, it is likely that Kindlin-2 additionally stabilizes MafA protein by inhibiting GSK-3-mediated degradation.

We observed a developmental effect in the mutant islets. The percentage of the $\beta$-cells in islets was significantly decreased, while that of the $\alpha$-cells was concomitantly increased, in mutant islets compared with their control islets. Reduced $\beta$-cell proliferation could contribute to this defect.

It is possible that the glucotoxicity, which was initially induced by Kindlin- 2 deficiency in $\beta$-cells, subsequently exacerbates the diabetic phenotypes in the mutant mice. It should be noted that the level of the fasting blood glucose in K2-RIP mice is much lower than that of the $d b / d b$ mice $(142 \pm 25 \mathrm{mg} / \mathrm{dl}$ for $K 2-R I P$ vs $327 \pm 104 \mathrm{mg} / \mathrm{dl}$ for $d b / d b$ ) (Fig. 2a, Supplementary Fig. 2). Thus, the glucotoxicity should be much subtle in K2-RIP mice relative to that in $d b / d b$ mice.

The RIP-Cre was reported to target Cre expression in certain areas in the brain ${ }^{55}$. This raises a possibility that Kindlin-2 loss in the brain could contribute to the phenotypes of K2-RIP mice. We observed an extremely low level of Kindlin-2 protein in the brain (Supplementary Fig. 7a, b). Furthermore, the levels of Kindlin-2 mRNA and protein were not markedly reduced in K2-RIP brain relative to those in control brain (Supplementary Fig. $7 \mathrm{c}-\mathrm{e}$ ). These results suggest that RIP-Cre may not target the Kindlin-2expressing brain cells. It is important to note that, while the $M I P$ CreERT was reported to be not expressed in the brain as demonstrated by the same study ${ }^{55}$, the $K 2^{f l / f l}$; MIP-CreERT mice (the present study) did display marked diabetes-like phenotypes (Fig. 6). Collectively, these observations do not support the idea that the diabetic phenotypes displayed by K2-RIP mice are due to Kindlin-2 loss in the brain.

Based on findings from this and other studies, we have proposed a working model to explain how Kindlin- 2 modulates $\beta$ cell function and $\beta$ cell mass (Fig. 7i). Kindlin-2 interacts with and stabilizes key transcription factor MafA in $\beta$ cells, thus increasing insulin expression. MafA also promotes $\beta$ cell proliferation and increases $\beta$ cell mass ${ }^{56}$. In the meantime, Kindlin- 2 upregulates the level of $\beta$-catenin protein by suppressing GSK-3 $\beta$ activity and/ or through a direct interaction with $\beta$-catenin ${ }^{42,43}$; this favors $\beta$ cell proliferation and survival and maintains $\beta$ cell mass and glucose homeostasis.

It is well established that Kindlin-2 functions as a coactivator of integrins, especially the $\beta$ integrins, and regulates cell-ECM adhesion, migration and signaling. However, it is interesting to compare the phenotypes from the deletion of Kindlin- 2 in $\beta$-cells $(K 2-R I P)$ with those from the deletion of $\beta 1$ integrin $(\beta 1-R I P)$ in the same mouse cell type. First, the defects displayed by K2-RIP mice are much more severe than those of the $\beta 1-R I P$ mice. K2$R I P$ mice display a severe growth retardation starting at 1 month of age, which is not observed in $\beta 1-R I P$ mice $^{57}$. Second, although both genotypes display a reduction in $\beta$-cell mass, K2-RIP mice exhibit a severe diabetic phenotype, including deficiencies in GTT and GSIS, while $\beta 1-R I P$ mice are not diabetic. Results from this study reveal that Kindlin-2 modulates MafA protein and activates Ins1 gene expression independent of its ability to activate $\beta$ integrin. Collectively, these findings suggest that Kindlin- 2 controls certain function of $\beta$-cells independent of $\beta 1$ integrin activation. Future study will dissect the integrin dependent and independent functions of Kindlin- 2 in $\beta$-cells.

\section{Methods}

Reagents. Tissue culture media RPMI 1640 and fetal bovine serum (FBS) were obtained from Thermo Scientific HyClone (Logan, UT, USA). Collagenase Type V, Ficoll PM 400, and glucose were purchased from Sigma-Aldrich (St. Louis, MO, USA), human regular insulin was from Eli Lilly (Indianapolis, IN, USA), and the insulin ELISA Kit from Alpco (Salem, NH, USA) (\#80-INSMSU-E01, E10)

Animal studies. The generation of Kindlin- $2^{f l / f l}$ mice was recently described ${ }^{34}$ RIP-Cre transgenic mice, in which a $668 \mathrm{bp}$ fragment of the rat insulin II gene promoter $(R I P)$ drives Cre recombinase expression in $\beta$-cells, were purchased from Jackson laboratory (Bar Harbor, ME, USA) ${ }^{36}$. To delete Kindlin- 2 expression in $\beta$ cells we bred Kindlin- $2^{f l / f l}$ mice to RIP-Cre mice and generated $\beta$-cell-selective Kindlin-2 knockout mice (Kindlin-2 $2^{R I P}$ or K2-RIP mice). RIP-Cre littermates were used as controls for this study. To delete Kindlin- 2 expression in adult $\beta$-cells, we bred Kindlin- $2^{f l f l}$ mice with $M I P$-Cre/ERT transgenic mice and generated inducible conditional Kindlin-2 knockout mice (K2f/f; MIPCreERT). TM (Sigma T5648) was administrated to 3-month-old mice through a daily peritoneal injection at the dosage of $100 \mathrm{mg} / \mathrm{kg}$ body weight for 5 days. This TM regimen dramatically reduced Kindlin-2 protein expression in islet cells (Fig. 6a). To activate $\beta$-catenin signaling in $\beta$-cells, we bred K2f/f; MIPCreERT with $\beta$-catenin $(e x 3)^{f / f l}$ mice and generated K2 $2^{f / f}$; MIPCreERT; $\beta$-cat $(\text { ex } 3)^{f l /+}$ mice, in which one copy of $\beta$-catenin exon 3 gene was floxed. $\beta$-catenin (ex3)fl/fl mice that harbor a mutant $\beta$-catenin allele whose exon 3 was floxed by loxP sequences were previously described ${ }^{58}$. Both $\beta$-catenin (ex3)fl/fl and $\beta$-catenin (ex3)fl/ mice were fertile and normal in body size. All research protocols were approved by the respective Institutional Animal Care and Use Committees of Rush University or Southern University of 
Science and Technology. We affirm that we have complied with all relevant ethical regulations for animal testing and research in this study.

\section{Lentiviral shRNA knockdown in primary human pancreatic islets. Human} pancreata were obtained from organ procurement organizations following formal research consent and then transported to the UVA Islet Microfluidic Laboratory of the University of Virginia for islet isolation. Human pancreatic islets were isolated by the UVA Islet Microfluidic Laboratory of the University of Virginia and used in this study. Human pancreatic islets were infected with Kindlin-2 shRNA (Sh-K2) or control (Sh-con) lentiviruses ${ }^{41}$. Two days after infection, protein extracts were isolated from both groups and subjected to Western blot analyses with indicated antibodies. The study protocol regarding the work with human islets in this study was approved by the Institutional Review Board of the University of Virginia.

GTT and GSIS and ITT assays. GTTs were performed on overnight-fasted (14-16 h) mice by i.p. injection of glucose ( $2 \mathrm{~g} / \mathrm{kg}$ of body weight). Blood glucose levels were measured at $0,30,60,90$, and $120 \mathrm{~min}$ after glucose injection using a glucose meter (Bayer HealthCare LLC, Mishawaka, IN, USA). For GSIS, mice were fasted overnight and injected intraperitoneally with glucose ( $2 \mathrm{~g} / \mathrm{kg}$ body weight). Blood insulin levels were measured using an ELISA kit from Alpco (Salem, NH, USA) at the indicated time points after glucose injection. ITTs were performed on fasted mice by the i.p. injection of recombinant human insulin (Indianapolis, IN, USA) at a dose of $1 \mathrm{U} / \mathrm{kg}$ of body weight; blood glucose levels were measured at 0 , $15,30,45$, and $60 \mathrm{~min}$ after insulin injection.

Isolation of pancreatic islets. Pancreatic islets isolation was performed as previously described ${ }^{59}$. Briefly, mice were sacrificed immediately before harvest. A laparotomy was performed, and the liver reflected back against the diaphragm. The common bile duct was located and clamped at the papilla of Vater. A $27 \mathrm{G}$ needle was inserted into the bile duct, and 2-3 ml cold collagenase type V (Sigma, \#C9263) solution $[1 \mathrm{mg} / \mathrm{ml}$ in Hanks buffered salt solution (HBSS)] was injected until the pancreas was visibly distended, followed by digestion for $20 \mathrm{~min}$ at $37^{\circ} \mathrm{C}$. The pancreas was then removed by gently tearing/cutting away from the attachment points. The digested pancreas tissues were washed three times using HBSS containing $0.2 \%$ bovine serum albumin (BSA), and subjected to discontinuous Ficoll gradient centrifugation. Islets were picked up manually under a dissecting microscope (Nikon Instruments Inc, Melville, NY, USA).

$\boldsymbol{\beta}$-cell area and $\boldsymbol{\beta}$-cell mass. Pancreatic sections were subjected to immunohistochemical staining for insulin as previously described ${ }^{60}$. Briefly, pancreases were dissected, weighed, and fixed in $4 \%$ paraformaldehyde overnight at $4{ }^{\circ} \mathrm{C}$. Tissues were then transferred to $70 \%$ ethanol and subsequently processed for paraffin sections. Five-micrometer sections were dewaxed and hydrated, and antigen retrieval was performed using $10 \mathrm{mM}$ sodium citrate buffer $(\mathrm{pH} 6.0)$ at $95^{\circ} \mathrm{C}$ for 10 min. Sections were incubated with anti-insulin (1:500; Abcam, ab7842) antibodies overnight at $4{ }^{\circ} \mathrm{C}$ in a humidified atmosphere. After washing, rabbit anti-guinea pig IgG/HRP (1:200; Dako, P0141) was added and incubated at room temperature for $45 \mathrm{~min}$. Signals were developed using the EnVision+System-HRP (DAB) kit (Dako North America Inc.) according to the manufacturer's instruction. Sections were then counterstained with hematoxylin. Pancreatic sections were imaged using a light microscopy (Leica Microsystems, Inc.). The insulin-positive area and pancreatic area were measured using Image Pro Plus 7.0 software (Rockville, MD, USA). The islet $\beta$-cell mass was examined using the following equation as described previously ${ }^{61}: \beta$-cell mass was calculated by dividing total insulin-positive area by total pancreatic area, multiplied by pancreas tissue weight. Approximately $6-8$ sections obtained from each tissue were analyzed.

Cell proliferation and apoptosis. Pancreatic sections from each group of mice were stained with antibodies against insulin or Ki67. Briefly, pancreases were dissected and fixed in $4 \%$ paraformaldehyde overnight at $4{ }^{\circ} \mathrm{C}$. Tissues were then transferred to $70 \%$ ethanol and processed for paraffin sections. Five-micrometer sections were dewaxed and hydrated. For Ki67 and insulin staining, antigen retrieval was performed using $10 \mathrm{mM}$ sodium citrate buffer $(\mathrm{pH} 6.0)$ at $95^{\circ} \mathrm{C}$ for 15 min. Slides were incubated with anti-insulin (1: 200; Abcam, ab7842) and anti-Ki67 (1:100; Abcam, ab15580) antibodies overnight at $4^{\circ} \mathrm{C}$ in a humidified atmosphere. After washing, appropriate Alexa Fluor 488-labeled goat anti-guinea pig IgG (1:200; Invitrogen, A11073) and Alexa Fluor 594-labeled donkey anti-rabbit IgG (1:2000; Invitrogen, A-21207) secondary antibodies were added and incubated at room temperature for $1 \mathrm{~h}$, followed by counterstaining with DAPI for nuclei. The slides were washed and mounted using a SlowFade ${ }^{\mathrm{TM}}$ Antifade kit (Invitrogen, \#S2828). The sections were examined using an LSM 700 laser scanning fluorescence confocal microscope running ZEN software (Zeiss). For quantitative analysis, ImageJ $(\mathrm{NIH})$ was used to count the number of DAPI positive cells within the insulin staining area. Insulin-positive cells and Ki67-positive cells were determined. Ki67-positive cells were normalized to total insulin-positive cells in the same area. Cell survival was evaluated using the In Situ Cell Death Detection Kit (Roche Applied Sciences, 11684795910) following the instructions from the manufacturer ${ }^{34}$. This method is based on the classical terminal deoxynucleotidyl transferase dUTP nick end labeling (Tunel) assay to examine apoptosis by detecting DNA fragmentation. Briefly, after dewaxation, antigen retrieval was performed using proteinase $\mathrm{K}(10 \mu \mathrm{g} / \mathrm{ml}$ in $10 \mathrm{mM}$ Tris/ $\mathrm{HCl}, \mathrm{pH}$ 7.4) at room temperature for $15 \mathrm{~min}$. The slides were washed twice with $1 \times$ PBS and incubated in TUNEL reaction mixture ( $50 \mu \mathrm{l}$ of Enzyme solution plus $450 \mu$ l Label Solution) for $60 \mathrm{~min}$ at $37^{\circ} \mathrm{C}$. The pancreas sections were further stained with an antibody insulin (1:200; Abcam, ab7842) and DAPI. The sections were examined using an LSM 700 laser scanning fluorescence confocal microscope running ZEN software (Zeiss). TUNEL-positive cells were normalized to total insulin-positive cells in the same area.

Measurement of $\mathbf{C a}^{2}+$ influx in primary islets. Islets attached to fibronectin $(10 \mu \mathrm{g} / \mathrm{ml}$, Sigma, \#F4759)-coated cover slips were cultured for 1 day and then loaded with the $\mathrm{Ca}^{2+}$-sensitive dye Fluo-4 AM (Invitrogen, Carlsbad, CA, USA, $\# \mathrm{~F} 14201,10 \mu \mathrm{M}$ ) and $0.1 \%$ Pluro (Invitrogen, Carlsbad, CA, USA, P3000MP) in image solution (containing $140 \mathrm{mM} \mathrm{NaCl}, 5 \mathrm{mM} \mathrm{KCl}, 5 \mathrm{mM} \mathrm{NaHCO}, 1 \mathrm{mM}$ $\mathrm{MgCl}_{2}, 10 \mathrm{mM}$ HEPES $\mathrm{pH} 7.4$, and $2 \mathrm{mM} \mathrm{CaCl}_{2}$ ) for $40 \mathrm{~min}$ at $37^{\circ} \mathrm{C}$. The cover slips with attached islets were placed to a perfusion chamber with a perfusion rate of $1.5 \mathrm{ml} / \mathrm{min}$. $\mathrm{Ca}^{2+}$ was measured using confocal microscopy (Nikon AlR, Nikon Corporation, Melville, NY, USA). Fluo-4 emission signals (F) were background subtracted and normalized to baseline fluorescence (F0), and changes of $\left[\mathrm{Ca}^{2+}\right] \mathrm{i}$ are presented as $\mathrm{F} / \mathrm{F}^{62}$.

High-fat diet treatment. Six-week-old male C57BI/6J mice were fed with standard chow or high-fat diet chow for 3 months. Both standard chow (ssniff R/MH) and high-fat diet chow (ssniff EF acc. D12492 (I) mod.) were obtained from sniff Spezialitaten GmbH (Soest, Germany).

GSIS assays in isolated islets. Islets were isolated and preincubated in 24-well plates for $2.5 \mathrm{~h}$ in RPMI 1640 media containing $10 \%$ FBS and $2.5 \mathrm{mM}$ glucose at 37 ${ }^{\circ} \mathrm{C}$ and $5 \% \mathrm{CO}_{2}$. After preincubation, islets were incubated in fresh media containing $16.7 \mathrm{mM}$ glucose solutions at $37^{\circ} \mathrm{C}$ and $5 \% \mathrm{CO}_{2}$ for $30 \mathrm{~min}$, the islets were sedimented and the supernatant was collected. The total protein in the islets was extracted by sonication in $300 \mu \mathrm{l}$ acid/ethanol $(0.18 \mathrm{M} \mathrm{HCl}$ in $95 \%$ ethanol). The levels of insulin in supernatant and cell extracts were determined using an insulin ELISA kit (ALPCO, Cat\#80-INSMSU-E01) according to the manufacturer's instruction ${ }^{63}$

DNA constructs and transfection and infection. pCMV/Flag-Kindlin-2 and pGEX/GST-Kindlin-2 fusion protein expression vectors were described previously ${ }^{64}$. To generate $\mathrm{pCMV} /$ Flag-Kindlin-2 expression plasmids expressing truncated forms of Kindlin-2, DNA elements encoding respective Kindlin-2 regions (aa $1-239$, aa $1-569$, aa 570-680) obtained by PCR were subcloned into the $\mathrm{KpnI} / \mathrm{XhoI}$ sites of pcDNA3.1(+)-3FLAG vector. The full-length GST-MafA fusion protein expression plasmid was constructed by subcloning the full-length MafA cDNA into the GST gene fusion vector pGEX-4T1 (Amersham Biosciences, Little Chalfont Buckinghamshire, UK) in correct reading frame. The $\mathrm{pCMV} / \beta$-gal expression vector has been described ${ }^{65}$. The HA-MafA expression vector was constructed by subcloning a full-length mouse MafA cDNA, which was obtained by PCR using a PCMV/MafA plasmid as a template, into the HindIII/Xbal sites of pcDNA3.1 $(+)-3 \mathrm{HA}$ vector in the correct reading frame. The pCMV/MafA template plasmid was kindly provided by Dr Takaaki Matsuoka of the Osaka University School of Medicine ${ }^{66}$. The rat 460-bp Ins1-luc reporter plasmid (p460rIns1luc) was kindly provided by Dr Michael S. Lan of the Louisiana State University Health Sciences Center $^{39}$. The p460rIns 1 C1mt-luc, which contains 4-bp substitution mutations (from TTACAGCTTCAGCC to TTACAGCTTactaC) in the MafAbinding site (C1) at positions $-118 /-122^{38,67}$, was generated from $p 460$ Ins 1 -luc by PCR amplification using a QuickChange ${ }^{\mathrm{TM}}$ XL Site-Directed Mutagenesis Kit (Stratagene, La Jolla, CA, USA) according to the manufacturer's instructions. All sequences were verified by automatic DNA sequencing.

For transfection, cells were plated on $35-\mathrm{mm}$ dishes at a density of $5 \times 10^{4}$ cells/ $\mathrm{cm}^{2}$. After $24 \mathrm{~h}$, cells were transfected with Lipofectamine 2000 (Invitrogen, Carlsbad, CA, USA) according to the manufacturer's instructions. Each transfection contained $0.25 \mu \mathrm{g}$ of the indicated reporter plasmids plus $1 \mathrm{ng}$ of pRLSV40, containing a cDNA for Renilla reformis luciferase to control for transfection efficiency. The cells were harvested and assayed using the Dual-Luciferase Assay Kit (Promega, Madison, WI, USA) on a GloMax multi detection system (Promega, Madison, WI, USA). For all transfection experiments, the amount of plasmid DNA was balanced as necessary with $\mathrm{pCMV} / \beta$-gal such that the total DNA was constant for each group.

Adenoviral vectors for enhanced green fluorescent protein (Ad/EGFP) and Kindlin-2 (Ad/Kindlin-2) were previously described ${ }^{68}$. Ad/Cre was previously described ${ }^{34}$. Cells were infected with adenovirus as previously described ${ }^{69}$. Briefly, Ad/EGFP or Ad/Kindlin-2 was added to INS-1 cells in $1 \%$ FBS and incubated for 1 $\mathrm{h}$ at $37^{\circ} \mathrm{C}$. Dishes were rotated every $5 \mathrm{~min}$ for the first $15 \mathrm{~min}$ to ensure that all of the cells were exposed to virus. After $1 \mathrm{~h}$, media were aspirated, and cultures were rinsed twice with serum-free medium, and then fresh media supplemented with $10 \%$ FBS were added to the dishes. The amount of adenovirus was balanced as necessary with Ad/EGFP such that the total amount was constant in each group. 
Quantitative real-time RT-PCR and Western blot analyses. RNA was isolated using the RNeasy Mini Kit (QIAGEN, Germantown, MD, USA, Cat\#74104) according to the manufacturer's instruction. Reverse transcription (RT) was performed using $1 \mu \mathrm{g}$ of denatured RNA and $100 \mathrm{pmol}$ of random hexamers (Applied Biosystem, Foster, CA, USA) in a total volume of $25 \mu$ containing $12.5 \mathrm{U}$ MultiScribe reverse transcriptase (Applied Biosystem, Foster, CA, USA). Quantitative real-time RT-PCR (qPCR) analysis was performed to measure the relative mRNA levels using the SYBR Green kit (Bio-Rad Laboratories Inc, Germantown, MD, USA). Samples were normalized to Gapdh expression. The DNA sequences of primers used for qPCR are summarized in Supplementary Tables 1 and 2. Western blot analysis was performed as previously described ${ }^{70}$. Briefly, protein extracts were fractionated on a 10\% SDS-PAGE gel and transferred onto nitrocellulose membranes (Schleicher \& Schuell, Keene, NH, USA). The membrane was blocked in 5\% nonfat milk in Tris-buffered saline/Tween 20 buffer; probed with primary antibodies, followed by incubation with secondary antibodies conjugated with horseradish peroxidase; and visualized using a Western Blotting Detection Kit (GE Healthcare, Chicago, IL, USA, cat\#: RPN2106). Antibodies used in this study are listed in Supplementary Table 3.

IHC and IF staining and confocal analysis. For IHC, $5-\mu \mathrm{m}$ sections were stained with antibodies or control IgG using the EnVision+System-HRP (DAB) kit (Dako North America Inc, Carpinteria, CA, USA) according to the manufacturer's instruction. For IF, cells were seeded and cultured on sterile glass cover slips in sixwell plates. After $24 \mathrm{~h}$, cells were fixed in $10 \%$ formaldehyde for $30 \mathrm{~min}$ at $37^{\circ} \mathrm{C}$. Cells were permeabilized with $0.2 \%$ Triton X-100 containing DAPI for $5 \mathrm{~min}$, and blocked with $2 \%$ BSA for $1 \mathrm{~h}$. The cells were then stained with a primary antibody (Supplementary Table 3) overnight at $4{ }^{\circ} \mathrm{C}$. After washing, cells were incubated with anti-mouse Alexa Fluor 594 (Invitrogen, Carlsbad, CA, USA) secondary antibodies (1:300) for $1 \mathrm{~h}$ at room temperature. Cells were then imaged using a confocal microscope (SP2-AOBS Leica Microsystems, Wetzlar, Germany).

Statistical analysis. The sample size for each experiment was determined based on our previous experience. Animals used in experiments of this study were randomly grouped. IHC, IF and histology were performed and analyzed in a double blinding way. Unpaired Student's $t$ test (two groups) and two-way ANOVA (multiple groups) were used. Results are expressed as mean \pm standard deviation (s. d.), as indicated in the figure legends. Differences with $P<0.05$ were considered statistically significant.

Reporting summary. Further information on research design is available in the Nature Research Reporting Summary linked to this article.

\section{Data availability}

All data generated for this study are available from the corresponding authors upon reasonable request. The source data underlying Figs. $1 \mathrm{~d}-\mathrm{f}, \mathrm{i}, 2 \mathrm{a}-\mathrm{i}, 3 \mathrm{a}, \mathrm{b}, \mathrm{d}-\mathrm{g}, \mathrm{i}, \mathrm{j}, 4 \mathrm{~b}-\mathrm{d}, \mathrm{b}$, $\mathrm{d}-\mathrm{k}, \mathrm{m}-\mathrm{p}, 6 \mathrm{c}-\mathrm{i}$, and $7 \mathrm{~b}-\mathrm{g}$ and Supplementary Figs. 1a-f, 2, 3a-c, 4a-d, 5, and 7a-e are provided as a Source Data file.

Received: 17 January 2018; Accepted: 16 December 2019; Published online: 24 January 2020

\section{References}

1. Sander, M. et al. Genetic analysis reveals that PAX6 is required for normal transcription of pancreatic hormone genes and islet development. Genes Dev. 11, 1662-1673 (1997).

2. Ohlsson, H., Karlsson, K. \& Edlund, T. IPF1, a homeodomain-containing transactivator of the insulin gene. EMBO J. 12, 4251-4259 (1993).

3. Sharma, A. \& Stein, R. Glucose-induced transcription of the insulin gene is mediated by factors required for beta-cell-type-specific expression. Mol. Cell. Biol. 14, 871-879 (1994).

4. Shieh, S. Y. \& Tsai, M. J. Cell-specific and ubiquitous factors are responsible for the enhancer activity of the rat insulin II gene. J. Biol. Chem. 266, 16708-16714 (1991)

5. Hang, Y. \& Stein, R. MafA and MafB activity in pancreatic beta cells. Trends Endocrinol. Metab. 22, 364-373 (2011).

6. Reza, H. M. \& Yasuda, K. Roles of Maf family proteins in lens development. Dev. Dyn. 229, 440-448 (2004).

7. Aramata, S., Han, S. I. \& Kataoka, K. Roles and regulation of transcription factor MafA in islet beta-cells. Endocr. J. 54, 659-666 (2007).

8. Zhao, L. et al. The islet beta cell-enriched MafA activator is a key regulator of insulin gene transcription. J. Biol. Chem. 280, 11887-11894 (2005).

9. Zhang, C. et al. MafA is a key regulator of glucose-stimulated insulin secretion. Mol. Cell. Biol. 25, 4969-4976 (2005).
10. Hou, J. C., Min, L. \& Pessin, J. E. Insulin granule biogenesis, trafficking and exocytosis. Vitam. Horm. 80, 473-506 (2009).

11. Rosengren, A. H. et al. Reduced insulin exocytosis in human pancreatic betacells with gene variants linked to type 2 diabetes. Diabetes 61, 1726-1733 (2012).

12. Ahren, B. Type 2 diabetes, insulin secretion and beta-cell mass. Curr. Mol. Med. 5, 275-286 (2005).

13. Rulifson, I. C. et al. Wnt signaling regulates pancreatic beta cell proliferation. Proc. Natl Acad. Sci. USA 104, 6247-6252 (2007).

14. Lai-Cheong, J. E., Parsons, M. \& McGrath, J. A. The role of kindlins in cell biology and relevance to human disease. Int. J. Biochem. Cell Biol. 42, 595-603 (2010).

15. Malinin, N. L., Plow, E. F. \& Byzova, T. V. Kindlins in FERM adhesion. Blood 115, 4011-4017 (2010)

16. Theodosiou, M. et al. Kindlin-2 cooperates with talin to activate integrins and induces cell spreading by directly binding paxillin. eLife 5, e10130 (2016).

17. Bottcher, R. T. et al. Kindlin-2 recruits paxillin and Arp2/3 to promote membrane protrusions during initial cell spreading. J. Cell Biol. 216, 3785-3798 (2017)

18. Sun, Y. et al. Kindlin-2 association with Rho GDP-dissociation inhibitor alpha suppresses Racl activation and podocyte injury. J. Am. Soc. Nephrol. 28, 35453562 (2017)

19. Hirbawi, J. et al. The extreme C-terminal region of kindlin-2 is critical to its regulation of integrin activation. J. Biol. Chem. 292, 14258-14269 (2017).

20. Rogalski, T. M., Mullen, G. P., Gilbert, M. M., Williams, B. D. \& Moerman, D G. The UNC-112 gene in Caenorhabditis elegans encodes a novel component of cell-matrix adhesion structures required for integrin localization in the muscle cell membrane. J. Cell Biol. 150, 253-264 (2000).

21. Siegel, D. H. et al. Loss of kindlin-1, a human homolog of the Caenorhabditis elegans actin-extracellular-matrix linker protein UNC-112, causes Kindler syndrome. Am. J. Hum. Genet 73, 174-187 (2003).

22. Montanez, E. et al. Kindlin-2 controls bidirectional signaling of integrins. Genes Dev. 22, 1325-1330 (2008).

23. Larjava, H., Plow, E. F. \& Wu, C. Kindlins: essential regulators of integrin signalling and cell-matrix adhesion. EMBO Rep. 9, 1203-1208 (2008).

24. Plow, E. F., Qin, J. \& Byzova, T. Kindling the flame of integrin activation and function with kindlins. Curr. Opin. Hematol. 16, 323-328 (2009).

25. Harburger, D. S., Bouaouina, M. \& Calderwood, D. A. Kindlin-1 and -2 directly bind the C-terminal region of beta integrin cytoplasmic tails and exert integrin-specific activation effects. J. Biol. Chem. 284, 11485-11497 (2009).

26. Fitzpatrick, P., Shattil, S. J. \& Ablooglu, A. J. C-terminal $\mathrm{COOH}$ of integrin betal is necessary for betal association with the kindlin-2 adapter protein. $J$. Biol. Chem. 289, 11183-11193 (2014).

27. Ali, R. H. \& Khan, A. A. Tracing the evolution of FERM domain of Kindlins. Mol. Phylogenet. Evol. 80, 193-204 (2014)

28. Bledzka, K. et al. Kindlin-2 directly binds actin and regulates integrin outsidein signaling. J. Cell Biol. 213, 97-108 (2016).

29. Jobard, F. et al. Identification of mutations in a new gene encoding a FERM family protein with a pleckstrin homology domain in Kindler syndrome. Hum. Mol. Genet 12, 925-935 (2003).

30. Svensson, L. et al. Leukocyte adhesion deficiency-III is caused by mutations in KINDLIN3 affecting integrin activation. Nat. Med. 15, 306-312 (2009).

31. Moser, M., Nieswandt, B., Ussar, S., Pozgajova, M. \& Fassler, R. Kindlin-3 is essential for integrin activation and platelet aggregation. Nat. Med. 14, 325-330 (2008).

32. Schmidt, S. et al. Kindlin-3-mediated signaling from multiple integrin classes is required for osteoclast-mediated bone resorption. J. Cell Biol. 192, 883-897 (2011).

33. Malinin, N. L. et al. A point mutation in KINDLIN3 ablates activation of three integrin subfamilies in humans. Nat. Med. 15, 313-318 (2009).

34. Wu, C. et al. Kindlin-2 controls TGF-beta signalling and Sox9 expression to regulate chondrogenesis. Nat. Commun. 6, 7531 (2015).

35. Zhang, Z. et al. Postnatal loss of kindlin-2 leads to progressive heart failure. Circ. Heart Fail 9, e003129 (2016).

36. Postic, C. et al. Dual roles for glucokinase in glucose homeostasis as determined by liver and pancreatic beta cell-specific gene knock-outs using Cre recombinase. J. Biol. Chem. 274, 305-315 (1999).

37. Sutherland, C., Leighton, I. A. \& Cohen, P. Inactivation of glycogen synthase kinase- 3 beta by phosphorylation: new kinase connections in insulin and growth-factor signalling. Biochem. J. 296(Pt 1), 15-19 (1993).

38. Matsuoka, T. A. et al. The MafA transcription factor appears to be responsible for tissue-specific expression of insulin. Proc. Natl Acad. Sci. USA 101, 2930-2933 (2004).

39. Wang, H. W. et al. Identification of an INSM1-binding site in the insulin promoter: negative regulation of the insulin gene transcription. J. Endocrinol. 198, 29-39 (2008).

40. Ma, Y. Q., Qin, J., Wu, C. \& Plow, E. F. Kindlin-2 (Mig-2): a co-activator of beta3 integrins. J. Cell Biol. 181, 439-446 (2008). 
41. Guo, L. et al. Kindlin-2 regulates mesenchymal stem cell differentiation through control of YAP1/TAZ. J. Cell Biol. 217, 1431-1451 (2018).

42. Yu, Y. et al. Kindlin 2 forms a transcriptional complex with beta-catenin and TCF4 to enhance Wnt signalling. EMBO Rep. 13, 750-758 (2012).

43. Ou, Y. et al. Kindlin-2 interacts with beta-catenin and YB-1 to enhance EGFR transcription during glioma progression. Oncotarget 7, 74872-74885 (2016).

44. Lin, J. et al. Kindlin-2 promotes hepatocellular carcinoma invasion and metastasis by increasing Wnt/beta-catenin signaling. J. Exp. Clin. Cancer Res. 36, 134 (2017).

45. Wang, Z. \& Thurmond, D. C. Mechanisms of biphasic insulin-granule exocytosis - roles of the cytoskeleton, small GTPases and SNARE proteins. J. Cell Sci. 122, 893-903 (2009).

46. Fan, F. et al. Dynamin 2 regulates biphasic insulin secretion and plasma glucose homeostasis. J. Clin. Investig. 125, 4026-4041 (2015)

47. Asahara, S. et al. Ras-related C3 botulinum toxin substrate 1 (RAC1) regulates glucose-stimulated insulin secretion via modulation of F-actin. Diabetologia 56, 1088-1097 (2013).

48. Zhu, X. et al. Microtubules negatively regulate insulin secretion in pancreatic beta cells. Dev. Cell 34, 656-668 (2015).

49. Naumann, H., Rathjen, T., Poy, M. N. \& Spagnoli, F. M. The RhoGAP Stard13 controls insulin secretion through F-actin remodeling. Mol. Metab. 8, 96-105 (2017).

50. Arous, C. \& Wehrle-Haller, B. Role and impact of the extracellular matrix on integrin-mediated pancreatic beta-cell functions. Biol. Cell 109, 223-237 (2017).

51. Ussar, S., Wang, H. V., Linder, S., Fassler, R. \& Moser, M. The Kindlins: subcellular localization and expression during murine development. Exp. Cell Res. 312, 3142-3151 (2006).

52. Guo, S. et al. The stability and transactivation potential of the mammalian MafA transcription factor are regulated by serine 65 phosphorylation. J. Biol. Chem. 284, 759-765 (2009).

53. Rocques, N. et al. GSK-3-mediated phosphorylation enhances Maftransforming activity. Mol. Cell 28, 584-597 (2007).

54. Han, S. I., Aramata, S., Yasuda, K. \& Kataoka, K. MafA stability in pancreatic beta cells is regulated by glucose and is dependent on its constitutive phosphorylation at multiple sites by glycogen synthase kinase 3. Mol. Cell. Biol. 27, 6593-6605 (2007)

55. Wicksteed, B. et al. Conditional gene targeting in mouse pancreatic $\beta$-Cells: analysis of ectopic Cre transgene expression in the brain. Diabetes $\mathbf{5 9}$, 3090-3098 (2010).

56. Eto, K. et al. MafA is required for postnatal proliferation of pancreatic betacells. PLoS ONE 9, e104184 (2014).

57. Diaferia, G. R. et al. betal integrin is a crucial regulator of pancreatic beta-cell expansion. Development 140, 3360-3372 (2013).

58. Harada, N. et al. Intestinal polyposis in mice with a dominant stable mutation of the beta-catenin gene. EMBO J. 18, 5931-5942 (1999).

59. Bertera, S., Balamurugan, A. N., Bottino, R., He, J. \& Trucco, M. Increased yield and improved transplantation outcome of mouse islets with bovine serum albumin. J. Transplant. 2012, 856386 (2012).

60. Zhu, K. et al. Impaired bone homeostasis in amyotrophic lateral sclerosis mice with muscle atrophy. J. Biol. Chem. 290, 8081-8094 (2015).

61. Iglesias, J. et al. PPARbeta/delta affects pancreatic beta cell mass and insulin secretion in mice. J. Clin. Investig. 122, 4105-4117 (2012).

62. Kanaporis, G. \& Blatter, L. A. The mechanisms of calcium cycling and action potential dynamics in cardiac alternans. Circ. Res. 116, 846-856 (2015).

63. Cai, E. P. et al. In vivo role of focal adhesion kinase in regulating pancreatic beta-cell mass and function through insulin signaling, actin dynamics, and granule trafficking. Diabetes 61, 1708-1718 (2012).

64. Qu, H. et al. Kindlin-2 regulates podocyte adhesion and fibronectin matrix deposition through interactions with phosphoinositides and integrins. J. Cell Sci. 124, 879-891 (2011).

65. Tu, Y., Wu, S., Shi, X., Chen, K. \& Wu, C. Migfilin and Mig-2 link focal adhesions to filamin and the actin cytoskeleton and function in cell shape modulation. Cell 113, 37-47 (2003).

66. Matsuoka, T. A. et al. Regulation of MafA expression in pancreatic beta-cells in $\mathrm{db} / \mathrm{db}$ mice with diabetes. Diabetes 59, 1709-1720 (2010).
67. Barrow, J., Hay, C. W., Ferguson, L. A., Docherty, H. M. \& Docherty, K. Transcription factor cycling on the insulin promoter. FEBS Lett. 580, 711-715 (2006).

68. Shi, X. et al. The MIG-2/integrin interaction strengthens cell-matrix adhesion and modulates cell motility. J. Biol. Chem. 282, 20455-20466 (2007).

69. Yang, S. et al. Foxo1 mediates insulin-like growth factor 1 (IGF1)/insulin regulation of osteocalcin expression by antagonizing Runx2 in osteoblasts. J. Biol. Chem. 286, 19149-19158 (2011).

70. Xiao, G. et al. Cooperative interactions between activating transcription factor 4 and Runx2/Cbfal stimulate osteoblast-specific osteocalcin gene expression. J. Biol. Chem. 280, 30689-30696 (2005).

\section{Acknowledgements}

We want to thank H. Henry Dong of the University of Pittsburgh for providing the INS-1 cells, Takaaki Matsuoka of the Osaka University Graduate School of Medicine for providing the pCMV/MafA expression plasmid ${ }^{66}$, and Michael S. Lan of the Louisiana State University Health Sciences Center for the rat Ins 1 gene promoter reporter plasmid ${ }^{39}$. This work was supported, in part, by the National Natural Science Foundation of China Grants (81991513, 81630066, 81870532, and 81972100), by National Institutes of Health Grant (AR068950), by the Guangdong Provincial Science and Technology Innovation Council Grant (2017B030301018), and by the Shenzhen Municipal Science and Technology Innovation Council Grants (KQJSCX20180319114434843, JCYJ20180302174117738, JCYJ20180302174246105, JSGG20180503182321166, JCYJ20150331101823686, and JCYJ20150831142427959).

\section{Author contributions}

Study design: G.X. and K.Z. Study conduct and data collection: K.Z., Y.L., H.C., Q.Y., L.M., G.K., J.W., Y.W. and G.X. Data analysis: G.X., K.Z., Y.L. and H.C. Data interpretation: G.X., K.Z., T.C., X.B., L.L., C.L., C.W., H.C. and D.C. Drafting the paper: G.X. G.X. and K.Z. take the responsibility for the integrity of the data analysis.

\section{Competing interests}

The authors declare no competing interests.

\section{Additional information}

Supplementary information is available for this paper at https://doi.org/10.1038/s41467 019-14186-y.

Correspondence and requests for materials should be addressed to C.W. or G.X.

Peer review information Nature Communications thanks the anonymous reviewer(s) for their contribution to the peer review of this work.

Reprints and permission information is available at http://www.nature.com/reprints

Publisher's note Springer Nature remains neutral with regard to jurisdictional claims in published maps and institutional affiliations.

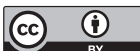

Open Access This article is licensed under a Creative Common Attribution 4.0 International License, which permits use, sharing, adaptation, distribution and reproduction in any medium or format, as long as you give appropriate credit to the original author(s) and the source, provide a link to the Creative Commons license, and indicate if changes were made. The images or other third party material in this article are included in the article's Creative Commons license, unless indicated otherwise in a credit line to the material. If material is not included in the article's Creative Commons license and your intended use is not permitted by statutory regulation or exceeds the permitted use, you will need to obtain permission directly from the copyright holder. To view a copy of this license, visit http://creativecommons.org/ licenses/by/4.0/.

(c) The Author(s) 2020 